\title{
DERECHO PROCESAL CONSTITUCIONAL Y DERECHO PROBATORIO CONSTITUCIONAL EN COLOMBIA ${ }^{1}$
}

\author{
NatTAN Nisimblat ${ }^{2}$ \\ Profesor de Derecho Procesal, Universidad Católica de Colombia \\ Nattan33 yahoo.com
}

RESUMEN: El presente documento da cuenta del desarrollo actual del Derecho Procesal Constitucional en Colombia, determina la aplicabilidad de los principios generales del proceso y de la prueba en los procesos contenciosos subjetivos, y resuelve sobre la existencia de un derecho probatorio constitucional.

ABSTRACT: This document reports on the current development of the Constitutional Procedural Law in Colombia, determines the applicability of general principles of the process and the evidence in subjective constitutional processes and resolves about the existence of a constitutional evidence law.

Palabras Clave: Derecho Procesal Constitucional, Derecho Probatorio, Derecho Constitucional.

KEYWORDS: Constitutional Evidence Law, Constitutional Law, evidence.

\section{INTRODUCCIÓN, PROBLEMA Y METODOLOGÍA}

\subsection{El problema}

Uno de los aspectos de mayor relevancia en el proceso de amparo constitucional, es el respeto por la dignidad humana y en tal virtud la protección de las garantías que se derivan del derecho superior al debido proceso imponen la aplicación de otros principios que rigen la actividad procesal en el trámite constitucional subjetivo.

La investigación se propuso el estudio del derecho procesal constitucional en Colombia y como objetivo específico el derecho procesal de las acciones constitucionales, marco dentro del cual se estudiaron los textos nacionales y

\footnotetext{
${ }^{1}$ Producto de investigación de la Universidad Católica de Colombia, proyecto "Derecho Procesal Constitucional Fase IV". Trabajo presentado el 9 de diciembre de 2011 y aceptado el 4 de julio de 2012.

${ }^{2}$ Abogado; Especialista en Derecho Procesal; Especialista en Derecho Probatorio; Profesor universitario; investigador de la Universidad Católica de Colombia. Miembro del Instituto Colombiano de Derecho Procesal; Miembro del Centro Colombiano de Derecho Procesal Constitucional.
} 
extranjeros que abordan el derecho procesal como una especialidad del derecho constitucional, así como la posible existencia de un derecho probatorio constitucional, interrogante que nace de la misma regulación procesal constitucional, del cual se desprenden dos objetivos específicos, como son: i. Determinar la existencia de principios procesales propios de las acciones constitucionales y en concreto de los procesos contenciosos subjetivos o de control concreto de constitucionalidad; ii. Identificar medios de prueba en particular del proceso de amparo y a partir de allí determinar la existencia de un derecho probatorio constitucional.

A partir de la sentencia T-002 de 1992 y luego con los pronunciamientos emitidos por la Corte Constitucional en las sentencias T-006 de 1992, T-406 de 1992, C-037 de 1996 y la reciente C-713 de 2008 mediante la cual efectuó la revisión oficiosa de constitucionalidad del Proyecto de ley No 286 de 2007 Cámara y No 023 de 2006 Senado, "por la cual se reforma la Ley No 270 de 1996, Estatutaria de la Administración de Justicia" (Ley No 1.285 de 2009), así como lo establecido en el Decreto No 1382 de 2000, el Auto No 004 de 2001 y el Auto No 100 de 2008, los conceptos de jurisdicción y competencia fueron redefinidos y limitados en sus alcances y efectos, lo cual ameritó definir el primero de los elementos que integran o componen el proceso judicial, como es el órgano jurisdiccional (el juez), para, a partir de allí, definir la actividad probatoria en el proceso constitucional, determinando sus partes (sujetos) y el objeto o pretensión procesal.

En 1991 la Constitución Política incorporó al ordenamiento jurídico interno colombiano el recurso de amparo, que desde 1948 había ordenado la Declaración Universal de los Derechos Humanos, denominado Acción de Tutela y con ella un nuevo concepto de jurisdicción constitucional. A partir de allí, la jurisprudencia de la Corte constitucional trazó unos lineamientos básicos para el adecuado manejo de las herramientas procesales que brindan tanto el artículo 86 de la Constitución, como el Decreto No 2591 de 1991, reglamentario de la Acción de Tutela, y el No 306 de 1992, reglamentario del 2591 de 1991, pues debe entenderse que la aplicación del principio de eficacia que ordena resolver el litigio en 10 días, no es óbice para que se desconozcan los demás derechos inherentes a la persona en el trámite de cualquier proceso judicial, bajo un principio rector denominado "audiencia bilateral" o "contradicción", que rige y determina la actividad probatoria.

En este marco se desenvolvió la investigación, buscando resolver una posible antinomia que se presenta al enfrentar los principios de eficiencia y eficacia en 
un proceso que propugna por el segundo, pero que a la vez debe respetar todas las garantías judiciales del derecho de defensa y contradicción.

Según el principio de contradicción, toda persona tiene el derecho a controvertir los hechos y las alegaciones que se formulen en su contra. Se tiene el derecho a controvertir, también, las decisiones judiciales, las opiniones de terceros, las pruebas, los dictámenes especializados, los procedimientos y en general toda actuación que redunde en provecho o perjuicio de la parte que asiste a juicio.

Se garantiza contradicción mediante la realización de determinados actos procesales, dentro de los que se cuentan los traslados de la demanda, de los recursos, de los peritajes, de las peticiones, de las pruebas aportadas, de las alegaciones, de los escritos, de las peticiones. Se garantiza contradicción mediante la permisión a las partes de participar en la práctica de pruebas y también mediante el aviso en tiempo de la realización de audiencias y diligencias (contradicción concentrada).

De rango constitucional, la contradicción hace parte inescindible del debido proceso. Un alegato incontrovertido, una prueba no conocida, un dictamen oculto, impiden la realización efectiva del derecho al debido proceso. Lo no controvertido no es pleno y sólo aquello que sea pleno será objeto de debate ${ }^{3}$.

En materia de Acción de Tutela, el principio de contradicción se ve limitado por el principio de eficacia que ordena al juez dictar la sentencia en el plazo perentorio de 10 días, situación que ha llevado a la Corte a diferenciar dos dimensiones del principio, una en función de la eficiencia y otra en función de la eficacia, pues según el perentorio mandato del artículo 86 de la Constitución, desarrollado por el artículo 29 del Decreto No 2.591 de 1991, el fallo debe dictarse en un término de 10 días, para lo cual el juez, tan pronto llegue al convencimiento respecto de la situación litigiosa, podrá proferirlo, según lo previsto en el artículo 22 ibidem.

Veritas in omnem partem sui eadem est: "La verdad es la misma en cada una de sus partes" ${ }^{\prime 2}$. Esta premisa, que informa el principio de verdad procesal,

\footnotetext{
${ }^{3}$ El derecho probatorio distingue los conceptos de "plena prueba" y "prueba sumaria", siendo la segunda, aquella que aún no ha sido controvertida pero que, en determinados asuntos, puede ser valorada por el juez; la segunda, por oposición, es la que ha sido sometida a contradicción por las partes, bien de manera concentrada (durante su producción), bien de manera difusa (en otras etapas del proceso), y que por lo tanto hace tránsito procesal a "plena".

${ }^{4}$ Nisimblat, Nattan, "Derecho Probatorio". In print, p. 86.
} 
encuentra limitaciones y excepciones en los distintos procedimientos y procesos en los que se propende por el amparo de derechos legal y constitucionalmente consagrados.

Taruffo 5 afirma que la discusión sobre si en el proceso se busca la verdad acerca de los hechos es absolutamente irrelevante. Los avances en la ciencia y la tecnología permiten al juez acercarse cada día más al conocimiento de los hechos; sin embargo, mientras se contempla el proceso como un debate dialéctico, se persistirá en la idea de la verdad probada.

\subsection{Diseño Metodológico}

Se trata de una investigación cualitativa, de corte holístico, bibliográfica, que incorpora doctrina nacional, extranjera e internacional, y jurisprudencia de la Corte Constitucional colombiana.

Es cualitativa bibliográfica pero de corte holístico, en la medida en que el análisis de la doctrina y la jurisprudencia constitucionales impiden una aproximación investigativa desde un solo paradigma, el cualitativo (mucho menos el cuantitativo), en virtud de: i. La diversidad de opiniones que se presentan en el seno de la Corte Constitucional, donde las decisiones son adoptadas por un número plural de magistrados divididos actualmente en nueve salas de revisión, cada una integrada por tres magistrados de distinta formación intelectual y aun política ${ }^{6}$. ii. La independencia existente entre las nueve salas, que, limitada únicamente por la unificación o la rectificación jurisprudencial, enriquece la jurisprudencia con variadas y disímiles posiciones frente a un mismo tema $\mathrm{y}^{7}$ iii. La ausencia de una verdadera doctrina procesal constitucional en la Corte, que permita identificar con claridad los

\footnotetext{
${ }_{5}^{5}$ TARUfFo, Michele. La prueba de los hechos. Colección de Estructuras y Procesos, serie derecho. Traducida por Jordi Ferrer Beltrán. Ed. Trotta. Madrid, 2002, p. 135.

${ }^{6}$ Constitución Política de Colombia, artículo 239. "La Corte Constitucional tendrá el número impar de miembros que determine la ley. En su integración se atenderá el criterio de designación de magistrados pertenecientes a diversas especialidades del Derecho. Los Magistrados de la Corte Constitucional serán elegidos por el Senado de la República para períodos individuales de ocho años, de sendas ternas que le presenten el Presidente de la República, la Corte Suprema de Justicia y el Consejo de Estado".

7 Acuerdo No 05 de 1992 (Reglamento de la Corte Constitucional), artículo 50. Salas de Revisión de Tutelas. "A medida que se repartan los negocios de tutela se irán conformando las Salas de Revisión, una por cada reparto, así: El Magistrado a quien corresponda alfabéticamente recibirlo, presidirá la Sala conformada con los dos Magistrados que le sigan en orden. La Sala decidirá por mayoría absoluta y el Magistrado disidente podrá salvar o aclarar su voto". Actualmente la Corte Constitucional cuenta con nueve salas de revisión, integradas cada una con tres magistrados.
} 
postulados y moduladores de la actividad judicial, situación que lleva a una investigación extramural, ubicada en los textos nacionales e internacionales de derecho procesal tanto civil como penal ${ }^{8}$.

De acuerdo con Hurtado Barrera, "es grande la confusión que reina en torno a conceptos y métodos utilizados como parte del proceso de investigación, y lo único que resalta claro y enfático para muchos teóricos, de tendencia positivista, es la creencia de que el único tipo de investigación válido y científico es la investigación confirmatoria de verificación empírica, la cual se basa en lo que se conoce como "método científico", y consiste en plantear un problema y formular hipótesis que luego se contrastan con base en un diseño de investigación, de preferencia, experimental. Este enfoque tradicional, al dejar de lado las modalidades de investigación no confirmatorias, ha desdeñado vertientes importantísimas del quehacer investigativo como la investigación evaluativa, la investigación-acción, la proyectiva, la predictiva, la prospectiva, etc. A lo largo de la historia también se han desarrollado y difundido otros modelos epistémicos, o concepciones de la investigación, con la idea de generar procesos más acordes con el quehacer científico; algunos de estos modelos epistémicos han sido agrupados por algunos autores (Cerda, 1991; Cook y Reichardt, 1986; Martínez, 1994), bajo la denominación del paradigma cualitativo de la investigación...La investigación holística abre una ventana novedosa que motiva y estimula a dar aportes propios y universales y ayuda al investigador a comprender las distintas fases por la que atraviesan los procesos creativos de la investigación. La investigación holística le devuelve a la inventiva humana y a la creatividad el lugar de privilegio que le corresponde dentro del proceso científico".?

La investigación se inició en el mes de agosto de 2008 (fase I), y continuó en 2009 (fase II), 2010 (fase III) y 2011 (fase IV), con la revisión de problemas relacionados con el proyecto como fueron los antecedentes de la jurisdicción constitucional en Colombia; Constitución e integración del Tribunal Constitucional colombiano; derechos fundamentales protegidos por la Tutela en Colombia; estado del arte en materia de procedimiento

\footnotetext{
${ }^{8}$ Constitución Política, artículo 239. "La Corte Constitucional tendrá el número impar de miembros que determine la ley. En su integración se atenderá el criterio de designación de magistrados pertenecientes a diversas especialidades del Derecho".

${ }^{9}$ Hurtado de Barrera, Jacqueline. En http://www.monografias.com/trabajos25/investigacion-holistica/ investigacion-holistica.shtml\#refer.
} 
constitucional en Colombia y medios de prueba, en particular y en el proceso de tutela.

La revisión de la jurisprudencia se realizó bajo la técnica de referencia al punto arquimédico, ingeniería de reversa, la telaraña y los puntos nodales de jurisprudencia ${ }^{10}$.

Mediante la ingeniería de reversa se partió de un pronunciamiento reciente, preferiblemente en el último mes o año, a partir del cual se identificaron las citas y las referencias horizontales realizadas por la Corte. Por referencia horizontal se entiende aquella que hace parte de las decisiones anteriores proferidas por el mismo cuerpo judicial.

Una vez identificadas las referencias, se construyeron mapas jurisprudenciales (la telaraña), de sentencias que desarrollaron un mismo punto de derecho y, con base en la convergencia y la concurrencia de las citas realizadas en cada una de ellas, se determinó aquella que constituye el punto de partida o inicial. Esta es la llamada sentencia arquimédica.

Una sentencia arquimédica es aquella que o bien desarrolla una teoría por primera vez o bien reconoce, recoge o implementa una doctrina del derecho que a partir de allí se incorpora a la jurisprudencia constitucional y entra en algunos casos a integrar el Bloque de Constitucionalidad. A partir de la sentencia arquimédica, la Corte construye nuevas teorías o reformula las ya planteadas hasta purificar o depurar una determinada doctrina, caso en el cual procede a unificar tales criterios en una sentencia denominada "hito". Es a partir de la sentencia hito que se encuentra el punto nodal. El nodo es un punto en el mapa (la telaraña), en el cual convergen una serie de decisiones anteriores y posteriores y sirve de referencia para guiar la labor de la Corte en sus futuras decisiones.

\section{Resultados obTEnidos}

En el proceso civil actual, la verdad es la sumatoria de lo alegado (hipótesis) más las pruebas de las alegaciones, caso en el cual el juez debe ajustarse, por una parte, a la teoría presentada por la parte, y por la otra, al soporte fáctico de la teoría (congruencia).

${ }^{10}$ López Medina, Diego Eduardo (2000). 


\subsection{El proceso constitucional y el proceso contencioso constitucional en Colombia}

Dos de las preguntas formuladas al inicio de la investigación ${ }^{11}$ se resolvieron afirmativamente: la primera se enmarcó en el tema de la litigiosidad de los derechos constitucionales, postulando el interrogante sobre si pueden considerarse como contenciosos y la segunda, derivada de la primera, si un proceso contencioso puede clasificarse en objetivo y subjetivo.

En las constituciones contemporáneas se observa una división más clara de los procedimientos que rigen el sistema de protección de los derechos consagrados en cada una de ellas, dando origen a trámites de índole administrativa o de índole jurisdiccional.

La actuación del Estado colombiano se caracteriza por estar provista de procedimientos. Así lo estatuyen, entre otros, los artículos 28, 29, 30, 31, 32, $33,83,84,85,86,93,103,104,105,106,122,138,139,153,150$ a 169 , 175, 186, 190, 202, 209, 212 a 215, 228, 229, 230, 238, 242 a 244, 251, 263, 339, 341, 342, 346 a 355 y 374 a 379 de la Constitución de 1991.

De su estudio se concluye que, al igual que el Derecho Procesal Administrativo, el Derecho Procesal Constitucional admite la existencia de un "Procedimiento Constitucional" y de un "Procedimiento Contencioso Constitucional", siendo este último el encargado de regular la actividad que procura por la protección de los preceptos constitucionales, sean éstos o no de carácter sustancial, siendo necesario aclarar que norma sustancial es aquella que, "en razón de una situación fáctica concreta, declara, crea, modifica o extingue relaciones jurídicas también concretas, entre las personas implicadas en tal situación" 12 " sin que tengan ese calificativo aquellas que se limiten a definir fenómenos jurídicos o a descubrir sus elementos, como tampoco las que regulan determinada actividad procesal"13.

Según lo establecido por la Corte Suprema de Justicia en sentencia del 28 de octubre de 2005 "...el rasgo característico de los preceptos sustanciales es el de consagrar verdaderos derechos subjetivos, de manera que dentro de esa categoría de

\footnotetext{
${ }^{11}$ La presente investigación fue inicialmente formulada en octubre de 2010 con unos objetivos generales y específicos. En julio de 2011 se formularon nuevas preguntas, las cuales se resuelven conjuntamente en el presente documento.

${ }^{12}$ Corte Suprema de Justicia, Sala de Casación Civil. CCLII, p. 208.

${ }^{13}$ Corte Suprema de Justicia, Sala de Casación Civil, Auto del 5 de mayo de 2000, exp. C-9114.
} 
normas sólo se hallan comprendidas aquellas que, al decir de esta Corporación 'en razón de una situación fáctica concreta, declaran, crean, modifican o extinguen relaciones jurídicas también concretas entre las personas implicadas en tal situación...', determinándose que de ese cariz no participan, en principio, entonces los preceptos que 'se limitan a definir fenómenos jurídicos o a describir los elementos de éstos o a hacer enumeraciones o enunciaciones, como tampoco las tienen las disposiciones ordenativas o reguladoras de la actividad in procedendo' (CLI, p. 241). Menos todavia las normas referentes a pruebas, en punto de las cuales ha expresado de continuo la Corte que no tienen rango sustancial".

Conforme con lo anterior y de acuerdo con el origen de la actuación, un proceso puede, o no, ser contencioso ${ }^{14}$. De antaño, la legislación administrativa ha establecido una clara diferenciación entre las normas que regulan el nacimiento y perfeccionamiento de sus actuaciones, dentro de las que se cuentan la comunicación con los administrados y aquellas que sistematizan los procesos que se surten ante los jueces en casos de controversia.

Las primeras hacen parte de lo que se denomina "Procedimiento Administrativo", el cual se ocupa, entre otras, de regular la actividad de la administración, el inicio de las actuaciones, el nacimiento de las obligaciones, el perfeccionamiento de los contratos, la comunicación con los ciudadanos. Las segundas, que aquí se denominan "Procedimiento Contencioso Administrativo", se encargan de regular la actividad de los jueces cuando las relaciones de la administración se tornan litigiosas y deben ser resueltas por un órgano con jurisdicción: el juez contencioso administrativo ${ }^{15}$ y así, de las primeras, se ocupa el Derecho Administrativo y, de las segundas, el Derecho Procesal Administrativo.

Siguiendo las reglas anteriores, las normas de Procedimiento Constitucional son aquellas que definen la forma como debe realizarse una determinada actividad, dentro de las que se encuentran las que regulan la formación y perfeccionamiento de aquellos actos previstos en la Constitución para su propia

\footnotetext{
${ }^{14}$ El Diccionario de la Real Academia Española (Vigésimo Segunda Edición) define el vocablo en su tercera acepción, derivada del derecho, así: "Se dice de los asuntos sometidos a conocimiento y decisión de los tribunales en forma de litigio entre partes, en contraposición a los de jurisdicción voluntaria y a los que estén pendientes de un procedimiento administrativo."

${ }^{15}$ Esta posición se fijó desde 2009, año en el cual se presentó una ponencia titulada "El derecho procesal constitucional como ciencia autónoma”. En 2011 el Congreso de la República de Colombia expidió la Ley No 1437, mediante la cual se derogó el Decreto No 01 de 1984, denominado "Código Contencioso Administrativo", reemplazándolo por un nuevo régimen procesal denominado "Código de Procedimiento Administrativo y de Procedimiento Contencioso Administrativo", lo cual ratifica lo expresado por el autor de estas líneas en cuanto a la naturaleza de los procesos administrativos.
} 
existencia como son su expedición, su reforma y su derogación; los relativos a la integración de los poderes públicos, tales como la elección del Presidente, del Vicepresidente, de los congresistas, de los superintendentes, de los gobernadores, de los alcaldes, de los ediles; la posesión de los servidores públicos; los mecanismos de participación ciudadana; los relativos a los estados de excepción; los que regulan la actividad legislativa; los que prevén la forma de integración de las corporaciones judiciales y de los órganos de control y, en general, las normas que prevén la forma como deben adelantarse las actuaciones del Estado, siempre que el procedimiento se encuentre plasmado en la Constitución. Del estudio de estas reglas se encarga el Derecho Constitucional y en concreto el Derecho Constitucional Colombiano.

Se denominará "Procedimiento Contencioso Constitucional" el previsto para la protección de las normas y los derechos constitucionales, cuando quiera que sea necesaria la intervención del juez constitucional. Algunas se encuentran insertas en la Constitución (Art. 86), otras en estatutos especiales proferidos por el Congreso de la República, el Gobierno Nacional o aún las propias corporaciones judiciales (reglamentos internos). Del estudio de tales normas se ocupa el Derecho Procesal y en concreto el Derecho Procesal Constitucional.

En este caso, de acuerdo con la naturaleza de la contención, es decir, del asunto debatido, el procedimiento será "Contencioso Objetivo" o "Contencioso Subjetivo", correspondiendo el primero al "Control Abstracto" y el segundo al "Control Concreto" de constitucionalidad.

La discusión acerca de si un proceso tiene o no naturaleza contenciosa, redunda en la aplicación del principio de contradicción y de audiencia bilateral, en la medida en que permite actuaciones que por regla general se encuentran reservadas a la parte, e impide, por la otra, la unilateralidad en la instrucción probatoria por parte del juez. Un proceso no contencioso, por naturaleza, es aquél en el cual no existe un demandante ni un demandado y por lo tanto, lo único que media es una petición que debe ser atendida por el juez, sin necesidad de dar traslado de ella a otros sujetos procesales, tal como ocurre, por ejemplo, en los procesos denominados como de "jurisdicción voluntaria" en el derecho interno colombiano, o las reclamaciones, quejas y peticiones que se elevan ante la Comisión Interamericana de Derechos Humanos en el Derecho Internacional, las cuales no tienen el carácter de contenciosas, aún en el evento en que promuevan pronunciamientos o la adopción de medidas, pues sólo tendrán tal carácter los procesos que ésta promueva en la Corte Interamericana de Derechos Humanos. También se le denomina "no contencioso" o "no litigioso", a aquel 
proceso que se surte sin la intervención de un juez, como el adelantado ante las autoridades administrativas en ejercicio del derecho de petición (Arts. $5^{\circ}$ y sucesivos del D. No 01 de 1984) y los recursos que se interponen contra las decisiones que ellas adopten, denominado "vía gubernativa" 16 .

Un ejemplo ilustra la discusión: En materia de inmunidades jurisdiccionales de los agentes y misiones diplomáticas acreditadas ante la República de Colombia $^{17}$, la Constitución Política establece que cuando se trate de asuntos contenciosos en que esté involucrada una misión diplomática o un agente diplomático, por virtud de lo previsto en el numeral quinto del artículo 235 de la Constitución, es competente la Corte Suprema de Justicia. Entonces, de instaurarse una Acción de Tutela contra una misión diplomática, cobijada por una inmunidad de tipo relativo ${ }^{18}$, debería asignarse competencia privativa a la Corte Suprema de Justicia en única instancia para tramitarla de considerarse que dicho trámite tiene el carácter de "contencioso", mas no así en el evento en que la tutela no fuera estimada como tal, caso en el cual sería competente cualquier juez de la república para tramitar una Acción de Tutela contra una misión diplomática acreditada ante el Gobierno de la República de Colombia.

\section{El proceso contencioso constitucional objetivo}

El proceso contencioso objetivo, público o popular de anulación por inconstitucionalidad, es aquel dirigido contra actos impersonales y abstractos, cuando entrañan una violación continua y permanente de la legalidad objetiva consagrada en la Constitución o en la ley, que afecta a una comunidad entera ${ }^{19}$.

\footnotetext{
${ }^{16}$ Esta denominación fue suprimida por la Ley No 1.437 de 2011, por la cual se expide el Código de Procedimiento Administrativo y de lo Contencioso Administrativo, cuya entrada en vigencia se determinó para el mes de junio del año 2012.

${ }_{17}$ Convención de Viena de 1961, aprobada por el Estado colombiano a través de la Ley 6a de 1972.

${ }^{18}$ Corte Suprema de Justicia, Sala de Casación Laboral, auto del 13 de diciembre de 2007, Rad. 32096 :

“...en materia laboral, distintos países, con fundamento en la costumbre internacional, han admitido su sujeción a las normas laborales internas. Entre ellos se encuentran: Estados Unidos, Polonia, Chile, República Islámica de Irán, Grecia, Rusia, Rumania, Francia, Tailandia, Indonesia, Brasil, Perú, Panamá, Guatemala, Suráfrica, Kenia, Honduras, Nueva Zelanda, Nicaragua, India, Italia, Austria, Hungria, Bulgaria y Argentina. De ello dan cuenta las comunicaciones pertinentes que éstos han enviado al Ministerio de Relaciones Exteriores de Colombia. Lo anterior pone de manifiesto, que la tesis de la inmunidad absoluta de jurisdicción de los Estados se ha debilitado, dando paso a otra-inmunidad relativa-, que no puede ignorarse, pues sería tanto como estar de espaldas ante un episodio de la humanidad que reclama su propio tratamiento."

${ }^{19}$ Consejo de Estado, sentencia 180 de mayo 16 de 1991.
} 
Característica esencial de este proceso es el control exclusivo de la constitucionalidad de las normas. Se desenvuelve en torno de dos extremos únicamente: la norma constitucional transgredida y el acto transgresor, sin que las posibles situaciones jurídicas que se interpongan cumplan papel alguno en la litis ${ }^{20}$, por lo que también se denomina "control objetivo de constitucionalidad" o "control abstracto de constitucionalidad".

Son ejemplos de tales actuaciones en el régimen jurídico colombiano, el control dirigido a que la Corte Constitucional excluya del ordenamiento las leyes contrarias a sus dictados, previo el ejercicio ciudadano de la acción pública, la acción de nulidad por inconstitucional confiada al Consejo de Estado, respecto de los decretos dictados por el Gobierno Nacional cuyo control no ha sido confiado a la Corte Constitucional; el control automático de los decretos legislativos dictados en ejercicio de las facultades conferidas por los artículos 212, 213 y 215 de la Constitución Política y la revisión previa de los tratados internacionales y las leyes que los aprueben.

El procedimiento contencioso objetivo de constitucionalidad se encuentra regulado actualmente en los artículos 153, 167, 214, 215, 241, 242, 243, 244, 379; decretos Nos. 01 de 1984 y 2.067 de 1991, los reglamentos internos de la Corte Constitucional ${ }^{21}$ y el Consejo de Estado ${ }^{22}$; la Ley No 270 de 1996, la Ley No 1.285 de 2009, Estatutarias de la Administración de Justicia ${ }^{23}$ y la Ley No 1.437 de 2011.

\section{El proceso contencioso constitucional subjetivo}

El proceso contencioso subjetivo hace parte en Colombia del control difuso e incidental de la Constitución y de las leyes. En los países europeos, este tipo de control no tuvo mayor desarrollo en sus orígenes en el siglo XIX. Sin embargo, con el transcurrir de los años, los cambios políticos y sociales de los nuevos Estados llevaron a reconsiderar la posición de la Constitución en sus

\footnotetext{
20 Ibid.

${ }^{21}$ Adoptado por el Acuerdo No 01 de 1992; adicionado por los Acuerdos Noos. 03 y 04 de 1992 y de nuevo codificado por el ACUERDo No 05 de 1992. Posteriormente, adicionado por los Acuerdos $\mathrm{N}^{\circ}$ s. 01 de 1995, No 01 de 1996, No 01 de 1997 y No 01 de 1999.

22 Acuerdo No 58 de 1999, Acuerdo No 45 de 2000, Acuerdo No 30 de 2002, Acuerdo No 31 de 2002, Acuerdo No 35 de 2001, Acuerdo No 55 de 2003.

${ }^{23}$ Revisadas mediante sentencias C-037 de 1996 y C-713 de 2008.
} 
sistemas internos; los órganos legislativos y judiciales habían desconocido el mecanismo casi hasta mediados del siglo XX cuando se reclamó la necesidad de dotar las Cartas fundamentales de herramientas para asegurar los derechos y garantías insertos en ellas. ${ }^{24}$

El proceso subjetivo es, en términos generales, el contencioso del restablecimiento y de la responsabilidad, el cual se desarrolla alrededor de tres elementos: la norma violada, el derecho subjetivo protegido por ella y el acto violatorio de aquélla y de éste ${ }^{25}$.

Estos tres elementos, norma violada, derecho subjetivo y acto violatorio, son propios de las actuaciones donde rige un principio de desconcentración del control de constitucionalidad, en las cuales se hace necesario, para remediar una situación concreta en la cual se han violado o amenazado derechos consagrados en la Constitución, aplicar de manera directa los postulados insertos en ella, razón por la cual a estos procesos también se les denomina "control subjetivo de constitucionalidad" o "control concreto de constitucionalidad" 26 , en virtud de la necesidad de resolver una situación concreta y subjetiva con las reglas plasmadas en normas superiores.

Son ejemplos de tales actuaciones la Acción de Tutela, la Acción Popular y el Habeas Corpus, de origen próximo en la Constitución de 1991, cada una con su procedimiento contencioso especial.

El procedimiento contencioso subjetivo constitucional se encuentra actualmente regulado en los decretos No 2.591 de $1991^{27}$ y No 306 de $1992^{28}$,

\footnotetext{
${ }^{24}$ La primera de las naciones en adoptar un control incidental difuso fue Portugal en 1914, cuando por disposición de la Ley Fundamental se estableció la prohibición para todos los poderes del Estado de suspender, separada o conjuntamente la Constitución, o limitar los derechos reconocidos en ella, y se facultó al Poder Judicial para velar por esa supremacía. Paralelamente se le otorgaba el poder de revisar los actos del legislativo cuando, a proposición de las partes interesadas en un proceso, se alegara la invalidez de una norma; en ese caso debía confrontar la norma acusada con la Constitución, estudiar su validez y determinar su compatibilidad (artículos $3^{\circ}$ y 63 de la Constitución de 1911).

${ }^{25}$ Ibid.

${ }^{26}$ Ver, además, Corte Constitucional: 1. Autos 374, 233, 067 de 2008; Autos 157, 143, 117, 116, 106 de 2007; Auto 100 de 2003; 071, 074, 100, 102 de 2002; 071, 087, 089, 090, 092 de 2001; 080 de 2000. 2. Sentencias: T-364, T-313, T-1275, C-713 de 2008, C-310, C-158 de 2007; C-890, C-421 de 2006, T-1024 de 2005, T-200 de 2004, SU-783 de 2003, C-292 de 2003, C-207 de 2003, T-365 de 2002, T-441 de 2000, T-142 de 1998, C-259 de 1995, C-805 de 1992.

${ }^{27}$ Por medio del cual se reglamenta la Acción de Tutela consagrada en el artículo 86 de la Constitución Política de Colombia.

${ }^{28}$ Por el cual se reglamenta el Decreto No 2.591 de 1991.
} 
la Ley No 472 de $1998^{29}$, la Ley No 1.095 de $2006^{30}$, la Ley No 1.437 de 2011 y el artículo $4^{\circ}$ de la Constitución, que reglamentan, en su orden, la Acción de Tutela, las acciones populares, el Habeas Corpus y la Excepción de Inconstitucionalidad ${ }^{31}$.

No hacen parte del procedimiento contencioso subjetivo constitucional las normas que gobiernan la Acción de Grupo, pues aunque comportan un control subjetivo y tienen origen en la Constitución, su thelos no es la protección de derechos constitucionales propiamente dichos (salvo las excepciones plasmadas en el artículo 87 de la Constitución y la Ley No 472 de 1998), sino derechos patrimoniales por la vía de un trámite que, según la Constitución, debe ser preferencial.

\subsection{Sobre la existencia del Derecho Probatorio Constitucional}

Otro de los problemas formulados en el proyecto de investigación es aquel que busca determinar la existencia de un derecho probatorio constitucional, a partir de la identificación de reglas y herramientas probatorias en los procesos contenciosos constitucionales.

Revisada la doctrina colombiana, se encontró con que un solo texto, publicado en 2007, da cuenta del derecho probatorio aplicado a los procesos contencioso objetivos constitucionales. Dicho documento, titulado "La prueba en los procesos constitucionales" de la profesora Anita Giacomette Ferrer de la Universidad de Los Andes y publicado por Señal Editora (290 pp.), contiene un prólogo escrito por el procesalista Eduardo Ferrer Mac-Gregor, quien afirma que el estudio "colma una laguna en la doctrina jurídica latinoamericana", sugiriendo con ello que a la fecha no existen documentos ni estudios sobre el derecho probatorio aplicado a los procesos constitucionales, apreciación que comparte el también prologuista de la misma obra Diego López Medina, para quien no existían a la fecha de publicación otros textos de similar linaje, lo que motivó la revisión de los textos que introducen y profundizan en el derecho procesal constitucional, encontrando que, salvo las necesarias

\footnotetext{
29 Por la cual se reglamenta el artículo 88 de la Constitución Política de Colombia en relación con el ejercicio de las acciones populares y de grupo y se dictan otras disposiciones.

${ }^{30}$ Por la cual se reglamenta el artículo 30 de la Constitución Política.

${ }^{31}$ Siendo la excepción de inconstitucionalidad un tipo de control abstracto que se practica en actuaciones concretas.
} 
referencias a los trámites probatorios de los procesos en particular, nada se dice respecto de una nueva disciplina, rama o estanco del derecho en materia procesal constitucional en Colombia.

La revisión de la doctrina extranjera, por su parte, incluyó los textos de autorizados tratadistas, algunos de ellos miembros del Instituto Iberoamericano de Derecho Procesal Constitucional, dentro de los cuales se destacan José Garberí Lobregat ${ }^{32}$, Eduardo Ferrer Mac-Gregor ${ }^{33}$, Domingo García Belaunde ${ }^{34}$, Oswaldo Alfredo Gozaíni ${ }^{35}$, Arturo Zaldívar Lelo De Larrea ${ }^{36}$, Pablo Luis Manili ${ }^{37}$, Rubén Hernández Valle ${ }^{38}$ y Luis Paulino Mora ${ }^{39}$, entre otros.

La lectura de los autores citados, más la revisión de más de $50^{40}$ sentencias y $10^{41}$ autos de la Corte Constitucional colombiana, que tratan directamente sobre el tema probatorio en Acción de Amparo y de Tutela, llevó a la conclusión de que no existe, o no ha sido reconocida, una Ciencia o Disciplina Probatoria Constitucional y ello en parte porque, como lo señala Rubén Hernández Valle, en los procesos de amparo constitucionales la violación o amenaza de un derecho fundamental se debe acreditar sin mayor debate probatorio, tal como se deduce de la regla consagrada en el artículo noveno del Código Procesal Constitucional de Perú ${ }^{42}$, según la cual en los procesos constitucionales no existe etapa probatoria y "sólo son procedentes los medios

32 Garberí Lobregat, José. (2009).

33 Ferrer Mac-Gregor, Eduardo. ( 2006). También Ferrer Mac-Gregor, Eduardo. (2008).

${ }^{34}$ García Belaunde, Domingo. (2001). También García Belaunde, Domingo. (2006).

${ }^{35}$ Gozaíni, Oswaldo Alfredo. (2006), pp. 201.

${ }^{36}$ Zaldívar Lelo De Larrea, Arturo. (2009).

37 Manili, Pablo Luis. (2010). También Manili, Pablo Luis. (2005).

${ }^{38}$ Hernández Valle, Rubén. (2006), pp. 183-196.

${ }^{39}$ Mora, Luis Paulino. (2005), pp. 169-187

40 Corte Constitucional, sentencias SU132-02, T-042-05, T-060-06, T-097-94, T-104-06, T-105-06, T-106-00, T-108-08, T-131-07, T-174-00, T-237-96, T-297-05, T-299-04, T-302-08, T-308-00, T-32996, T-340-00, T-363-03, T-367-07, T-383-98, T-449-01, T-452-01, T-464A-06, T-476-98, T-484-06, T-489-01, T-500-94, T-523-01, T-578-98, T-586-02, T-591-08, T-593-92, T-599-03, T-600-09, T-69602, T-699-02, T-739-98, T-820-99, T-864-99, T-883-04, T-883-06, T-884-04, T-970-99, T-990-02, T-1008-01, T-1056-01, T-1088-01, T-1181-00 у T-1630-00.

${ }^{41}$ Corte Constitucional, Autos A049-06, A056-06, A073-07, A073-98, A114-05, A121-00, A135-08, A152-00, A161-03 y A206-06.

${ }^{42}$ Perú, Ley No 28237, promulgado el 28-05-2004, publicado el 31-05-2004, vigente a partir del 31 11-2004. 
probatorios que no requieren actuación, lo que no impide la realización de actuaciones probatorias que el juez considere indispensables, sin afectar la duración del proceso", lo cual impide el decreto de aquellas pruebas que requieran de práctica o producción procesal tal como lo son el testimonio, la declaración de parte, la inspección judicial, y el peritaje, entre otros, por requerir de un período probatorio.

Sin embargo, la investigación en Colombia arrojó resultados particulares en cuanto a la admisibilidad de la prueba en los procesos de tutela, su conducencia, la forma de decretarla, y la forma de valorarla, encontrando que, en primer lugar, no existe la restricción consagrada en el Código Procesal Constitucional peruano, tal como se desprende de la lectura del artículo 22 del Decreto No 2.591 de $1991^{43}$, según el cual "el juez, tan pronto llegue al convencimiento respecto de la situación litigiosa, podrá proferir el fallo, sin necesidad de practicar las pruebas solicitadas", lo cual implica que en el trámite de amparo son admisibles todos los medios de convencimiento consagrados en la legislación procesal civil colombiana (aplicable al proceso de tutela por disposición del Decreto No 306 de 1992 que reglamentó el Decreto No 2.591 de 1991), como son el testimonio, la peritación, la declaración de parte, la confesión, los indicios, la inspección judicial, las pruebas trasladadas, los documentos y los informes.

En segundo lugar, la jurisprudencia nacional colombiana ha aceptado que en materia probatoria se aplica el principio denominado por la doctrina procesal como "principio de adaptación del procedimiento a las exigencias de la causa" ${ }^{44}$, cuyo origen se remonta a la expresión latina mutatis mutandis (cambiando lo que se deba cambiar), según la cual, cuando un procedimiento remita a las normas de otro (en este caso el constitucional al civil en materia probatoria, según lo previsto en el Decreto No 306 de 1992), se aplicarán las reglas del segundo, siempre y cuando sean compatibles con la causa adelantada, evento en el cual, de ser necesario, algunas reglas y principios como el de conducencia (idoneidad), alteridad (intersubjetividad) y sana crítica (lógica, sentido común, experiencia y ciencia), deberán ser atemperados al fin procesal perseguido, esto es, la defensa de los derechos fundamentales, pues aunque es claro que el brevísimo proceso de tutela se desarrolla en todas sus etapas en el lapso de 10 días, no por ello debe desconocerse el papel preponderante que

${ }^{43}$ Colombia, Decreto No 2.591 de 1991, D.O. 40.165 de 19 de noviembre de 1991

44 Calamandrei, Piero, 1973, p. 376. 
cumple el principio de necesidad ${ }^{45}$ y sus reglas de conducencia, pertinencia y utilidad, así como la regla de itinerancia de la prueba (petición, decreto, práctica, valoración) ${ }^{46}$, pues aunque el fallo debe proferirse en 10 días, si una prueba debe ser valorada en sentencia, el único medio para asegurar legalidad, licitud y contradicción, será respetando, en concordancia con el principio de adecuación ${ }^{47}$, el principio de necesidad probatoria, según el cual, toda decisión deberá fundarse en pruebas regular y oportunamente allegadas al proceso.

El citado autor costarricense cita doce principios generales de la prueba con sus respectivas adaptaciones al proceso constitucional como son la eficacia jurídica, la unidad probatoria, la comunidad, el interés público en función de la prueba, la lealtad o probidad (también denominado veracidad), la contradicción, la publicidad, la legitimación, la preclusión, la libertad, la pertinencia, la utilidad, la idoneidad y el principio de la carga de la prueba ${ }^{48}$, a los cuales se suman principios los postulados por el autor del presente escrito en 2009, denominados necesidad, autorresponsabilidad, inmediación, concentración, inmaculación, originalidad, mismidad, libertad, duda o in dubio y rogación, definiendo la influencia de cada uno de ellos en el proceso constitucional de tutela ${ }^{49}$.

${ }^{45}$ El principio de necesidad es el resultado de la prohibición constitucional del fallo sin pruebas. También es el resultado de la prohibición internacional de la decisión por sospecha, en oposición a la decisión por indicio. De acuerdo con la legislación procesal colombiana, toda decisión deberá fundarse en pruebas regular y oportunamente allegadas al proceso. Este concepto, que encierra varias previsiones de contenido sustancial, obliga al intérprete y por lo tanto al operador judicial a distinguir los "momentos procesales de la prueba", también conocidos como el iter o el sendero probatorio. De la redacción y contenido del principio de necesidad surgen las siguientes reglas: 1 . No podrá valorarse la prueba que no fue pedida en tiempo, decretada legalmente y practicada en debida forma; 2 . No podrá practicarse la prueba que no fue legalmente decretada; 3 . No podrá decretarse la prueba que no fue oportunamente pedida o aportada o que, además, sea inconducente, impertinente o inútil, y 4 . No podrá pedirse o aportarse la prueba en oportunidad distinta que la prevista en la ley. Las anteriores reglas obedecen a cada una de las etapas del iter probatorio, como son: 1. Petición y aporte; 2. Decreto; 3. Práctica y; 4. Valoración.

${ }^{46}$ El iter o camino, es el sendero que debe recorrer la prueba para que pueda ser valorada en la sentencia o en la providencia, pues si bien se admite que la decisión debe fundarse en medio de prueba, también se admite que la valoración no es el resultado del capricho del juez.

47 También denominado "adaptabilidad". Consiste en la libertad de adaptar el procedimiento a las necesidades del proceso, siempre que con ello se logre su finalidad y no se viole el derecho de defensa o de audiencias.

${ }^{48}$ Hernández Valle, Rubén, (2006), p. 184.

49 Nisimblat, Nattan, (2009). En este libro se abordan los principios del derecho probatorio desde la teoría general del proceso. El autor ilustra el camino o iter de la prueba en los procesos judiciales, aplicado al proceso de tutela. 


\subsection{Herramientas probatorias y medios de prueba en particular}

En procesos como el constitucional de tutela, donde lo que se busca es la protección de un derecho que no es de libre disposición por tener el carácter de fundamental (thema probandum), el dominus de la prueba lo tiene el juez, quien debe sustraerse de los límites impuestos por las teorías e hipótesis formuladas en los alegatos (congruencia), para determinar si un hecho que es relevante para el proceso ocurrió (objeto de prueba y pertinencia), y para ello debe valerse de las herramientas procesales que la ley y la constitución le brindan, atendiendo a los medios de prueba previstos para el proceso en particular y a la conducencia y eficacia de cada uno de ellos, pues según las reglas especiales que rigen los procesos, lo que es conducente en un trámite no lo será igualmente para otro, por lo que es imperativo, como afirma Hernández Valle, modular la actividad procesal con los principios del derecho procesal general y éstos, a su vez, con los principios del derecho procesal constitucional, determinados en el artículo 86 de la Constitución Política de Colombia y en el artículo $3^{\circ}$ del Decreto 2591 de 1991, como son la publicidad, la prevalencia del derecho sustancial, la economía, la celeridad y la eficacia.

Ejemplos de ello se encontraron en cada uno de los medios de prueba individualmente considerados en procesos de distinto linaje. Así, mientras en el proceso civil no se admite copia simple de un documento en el que consta un contrato cuando en el documento original no intervinieron las mismas partes que actúan en el proceso ${ }^{50}$, tal restricción no impera en el proceso laboral, lo cual evidencia el aligeramiento, los principios de mismidad y originalidad, así como la regla de conducencia en materia de idoneidad de documentos demostrativos de hechos; mientras en el derecho procesal de familia no es admisible la prueba del estado civil por declaración extrajudicial, a efectos de reconocimiento de pensiones, en el derecho procesal de la Acción de Tutela sí lo es ${ }^{51}$, (adecuación del principio de conducencia) y mientras en el derecho procesal administrativo no se presume la autenticidad de documentos y memoriales, en el derecho procesal civil es medio legal y admisible de prueba un documento o memorial que no ha sido autenticado o presentado

\footnotetext{
${ }^{50}$ Ley No 1.395 de 2010. D.O. No 47.768 de 12 de julio de 2010.

${ }^{51}$ Por disposición expresa del Código Civil, del Decreto No 960 de 1970 y la Ley No 979 de 2005 , la prueba del Estado Civil será el registro civil de nacimiento, el acta de matrimonio, la partida eclesiástica, el acta de conciliación en materia de unión marital, la escritura pública o la sentencia ejecutoriada.
} 
personalmente ante notario (L. 1395 de 2010 que morigeró la exigencia del tradicional principio de originalidad).

Otros ejemplos ilustran la conclusión: i. En el proceso civil es admisible la prueba de la confesión (art. 175 C.P.C.), pero no así en el proceso contencioso administrativo (arts. 168 C.C.A. y 199 del C.P.C.); sin embargo, a pesar de que en este último no se admite la confesión expresa ni tácita, en el trámite de tutela se reguló una situación intermedia que apunta a una confesión ficta por parte del servidor público que es sujeto pasivo de una demanda constitucional de amparo, tal como se desprende de la lectura del artículo 20 del Decreto No 2.591 de 1991, que estableció que "si el informe no fuere rendido dentro del plazo correspondiente, se tendrán por ciertos los hechos". ii. La tradicional carga estática de prueba consagrada en el artículo 177 del Código de Procedimiento Civil u onus probandi, cede o se invierte en el proceso constitucional de tutela a favor de la parte menos favorecida, en aplicación de los principios de igualdad y de solidaridad, ambos de rango constitucional. iii. Son notorias las facultades oficiosas del juez constitucional (D. No 2.591 de 1991, art. 21 y Decreto No 2.067 de 1991, artículos 12 y 13), lo cual no se observa en la regulación procesal administrativa contenida en el Decreto No 01 de 1984 y en la Ley No 1.437 de 2011, que consagran una jurisdicción eminentemente rogada; iv. En materia penal se evidencia que son amplias las potestades oficiosas en materia probatoria de los jueces penales con función de control de garantías, bajo la perspectiva de su doble militancia entre la Jurisdicción Ordinaria y la Constitucional, concluyendo que se trata de un juez que itera entre las dos, conclusión que lleva a afirmar que, mientras el juez funge como órgano constitucional, plenas son sus facultades para decretar y practicar pruebas oficiosamente, lo cual encuentra restricción cuando cumple funciones ordinarias dentro del juicio bajo las reglas adversariales del sistema penal de corte acusatorio consagrado en la Ley No 906 de $2004^{52}$. v. Es evidente que la prueba por excelencia en los procesos contenciosos constitucionales es la prueba por informes (D. No 2.591 de 1991, art. 19 y Decreto No 2.067 de 2001, art. 13), la cual tiene un trato definido en el Código de Procedimiento Civil (art. 243 C.P.C.), pero no así en el proceso contencioso

\footnotetext{
52 El artículo 361 de la ley No 906 de 2004, que restringió las potestades oficiosas del juez penal, fue declarado exequible por la Corte Constitucional mediante sentencia C-396 de 2007. Sin embargo, la Corte Suprema de Justicia declaró en sentencia 24438 del mismo año, que este mismo juez tiene amplias facultades oficiosas cuando se trate de la protección de los principios y derechos constitucionales.
} 
constitucional, bien sea el objetivo de constitucionalidad o los subjetivos de Habeas Corpus y Tutela.

Los anteriores ejemplos demuestran que la prueba de los hechos y la disciplina que se encarga de estudiar sus reglas, no es transversal en el derecho, razón por la cual ameritó adelantar una investigación que diera cuenta de dicho problema, esto es, si en efecto existe un derecho, ciencia o disciplina probatoria constitucional, a partir de la identificación de problemas vigentes en los procesos constitucionales y aquellos que se adelantan ante los jueces ordinarios, producto de las constantes reformas legislativas (hiperinflación), con marco en la acción consagrada en el artículo 86 de la Constitución (Acción de Tutela), el Decreto No 01 de 1984 (Código Contencioso Administrativo), el Decreto No 2.591 de 1991 (Reglamentario de la Tutela), el Decreto No 2.067 de 1991 (procesos en y ante la Corte Constitucional), la Ley No 270 de 1996 (Estatutaria de la Administración de Justicia), la Ley No 472 de 1998 (populares y grupo), la Ley No 1.395 de 2010 (descongestión judicial) y la Ley No 1.437 de 2011 (reforma al proceso contencioso administrativo).

\section{DisCUSIÓN}

La investigación en Derecho Procesal Constitucional ha permitido abordar los problemas actuales del derecho procesal general y el probatorio, en virtud de la posibilidad de enfrentar los retos que impone la disciplina bajo perspectivas de orden humano y social.

La Constitución Política de Colombia de 1991 introdujo importantes variaciones a la estructura de la administración de justicia, creando un completo sistema de jurisdicción constitucional ${ }^{53}$, en el que se ha adoptado un régimen de garantías para la salvaguarda de la Carta Fundamental, bajo un sistema mixto de control.

Cappelletti, en su momento, la llamó la jurisdicción de la libertad ${ }^{54}$, en el que el sistema jurisdiccional en torno de la Constitución optó por la solución, cada vez más cercana a los ciudadanos, de los problemas sociales fundamentales que aquejan al país, como producto de los cambios jurídico-políticos sufridos en el siglo pasado y que abrieron el paso a las tendencias del nuevo milenio. A este concepto, que denominó jurisdicción constitucional de la libertad, y que ha

53 Corte Constitucional, Sentencias: T-006 de 1992, C-037 de 1996 y C-713 de 2008.

${ }_{54}$ Concepto desarrollado en el libro La Giurisdizione constituzionale della libertà, Milán, 1976. 
seguido un importante sector de la doctrina contemporánea, ${ }^{55}$ deben agregarse los que Héctor Fix-Zamudio ha desarrollado siguiendo las ideas del procesalista italiano, con la denominación de jurisdicción constitucional orgánica y jurisdicción constitucional transnacional.

A partir de 1991, la Constitución dejó de ser estudiada y aplicada como una fórmula política inerte, para afirmarse a sí misma como una norma jurídica ${ }^{56}$, que ejerce supremacía sobre el orden jurídico, tanto material como formal ${ }^{57}$, dotando, por una parte, de competencias a los órganos del Estado para ejercer sus funciones, y legitimando, por la otra, las actuaciones de los poderes constituidos, con base en la representación popular que comporta su articulado, para convalidar o anular las normas que se opongan a ella.

La idea de establecer una norma como lex superior, proviene de las teorías del pacto social y en especial la doctrina de Jhon Locke, que propende por el establecimiento de un pacto básico y superior, que constituya el fundamento de todo sistema jurídico, así como la declaración de independencia de los Estados Unidos de Norteamérica en el siglo XVIII, en la que se sentaron las bases de obediencia a una Ley Fundamental que previniera a los poderes soberanos de imponer leyes contrarias a la voluntad general, soberana y popular radicada en los habitantes del nuevo Estado.

La "Supreme Law of the Land", libró a los colonos del mandato inglés y declaró la independencia absoluta de su reinado. Para ello, en la sección segunda del artículo VI se determinó: "This Constitution, and the laws of the United States which shall be made, in persuance thereof; and all treaties made, or which shall be made, under the authority of the United States, shall be the supreme law of the land; and the judges in every state shall be bound thereby anything in the Constitution or laws of any state to the contrary notwithstanding".

La doctrina constitucional ha coincidido en señalar este artículo como la génesis normativa del concepto de valor superior de la Constitución, de donde posteriormente se derivaría la "Doctrina de la Revisión Judicial" (Judicial Review).

En Francia, las ideas revolucionarias provocaron movimientos de constitucionalismo como expresión de la voluntad soberana popular, obra de un

\footnotetext{
${ }^{55}$ Cfr., entre otros, Fix-Zamudio, Héctor, y Valencia Carmona, Salvador, pp. 205 y ss.; Cascajo Castro, José Luis, (1975), pp. 148 y ss.

${ }^{56}$ García de Enterría, Eduardo y Fernández, Tomás Ramón. (1995), p. 161.

${ }^{57}$ Corte Constitucional, sentencia T-406 de 1992. Magistrado Ponente Dr. Ciro Angarita Barón.
} 
poder constituyente superior y protector de los recién proclamados Derechos del Hombre $e^{58}$; sin embargo, fuerzas contrarias llevaron a fenecer el intento, reemplazándolo por la idea posnapoleónica del movimiento de restauración, que posicionaba a la Constitución como una expresión de la voluntad divina del Rey, en la cual se otorga plena legitimidad al poder legislativo, como representante directo del pueblo.

En 1920, con la obra de Hans Kelsen, plasmada en la Constitución austríaca $^{59}$, se estableció el control constitucional sobre los actos del legislativo, con una variante respecto del sistema americano adoptado por la doctrina Marshall: se optó por la introducción de un sistema de control concentrado en un tribunal constitucional, el cual era el encargado de velar por la guarda de la supremacía de la Constitución y conocer de los recursos incidentales que formularan prejudicialmente los funcionarios de administración de justicia. Los fallos que dictara el tribunal constitucional en el evento de formularse la cuestión prejudicial, tendrían efectos generales, erga omnes.

Esta particularidad del sistema propuesto por Kelsen y adoptado por la Constitución austríaca ${ }^{60}$ daba un nuevo giro al mecanismo de control de los actos legislativos. Cuando se planteara una cuestión prejudicial ante el Tribunal, el resultado era remover la norma del ordenamiento y no como se habría planteado en Estados Unidos, donde el fallo invalidaba la norma incompatible pero en el caso concreto y con efectos particulares.

La revolución era evidente, pues el método de control planteado por Kelsen revestía nuevo poder legislativo, en este caso negativo, que revisaba la validez de las normas del ordenamiento en función de la Constitución y las anulaba.

Bajo el punto de vista organicista, la concepción de Constitución como norma jurídica implica una revisión general de la teoría de la división de poderes.

\footnotetext{
${ }^{58}$ Declaración de los derechos del hombre y del ciudadano de 1789.

59 La Constitución austríaca de 1920, de cuyo proyecto Kelsen fue uno de los redactores, instituía en su título VI, apartado b al "Tribunal Constitucional" que era competente para: 1. Decidir sobre legalidad de las ordenanzas de las autoridades federales o estatales y, en caso de que fueran consideradas inconstitucionales (Artículo 140); 3) recibir y resolver las impugnaciones que fueran presentadas en contra de las elecciones del Consejo Nacional, del Consejo Federal, de las dietas y de las asambleas representativas, y decidir también sobre la revocación del mandato de alguno de sus miembros (artículo 141); 4) pronunciarse sobre la eventual responsabilidad jurídica del presidente de la Federación, y de los miembros del gobierno de un Estado (artículo 142), y 5) dar respuesta, una vez agotada la vía gubernamental, a los recursos interpuestos por la violación de los derechos garantizados por la Constitución provocada por decisiones o actos administrativos (artículo 144).

${ }^{60}$ Véase Bongiovanni, G. (1998), pp. 143 y ss.
} 
Tradicionalmente la función judicial se ha entendido como una labor silogística, en la que los jueces están llamados a establecer una tipicidad de los casos sujetos a su decisión, frente a las normas previamente establecidas, sin ningún poder interpretativo ni creativo, a lo cual reacciona Recasens Siches postulando su logos de lo razonable como una alternativa al silogismo judicial ${ }^{61}$.

Ihering ${ }^{62}$, por el contrario, señaló que uno de los errores en la aplicación del derecho "consiste en suponer que deba considerarse un orden jurídico positivo como emancipación deductiva de una idea o de un plan, olvidando que el hecho de que las ideas se presenten compuestas de tal o cual modo no depende de exigencias lógicas, sino que depende precisamente del hecho de que en el modo como se presentan pueden satisfacer las necesidades de la vida social"63. El juez es, entonces, creador y a la vez controlador de los actos de los demás poderes, tal como lo sostiene la doctrina constitucional norteamericana ${ }^{64}$.

En los Estados Unidos, a partir de la "Doctrina de la Revisión Judicial" o "Judicial Review", que tuvo sus orígenes en el caso Marbury vs. Madison, (5 U.S. 81 Cranch 137-1803), la Corte Suprema de Justicia se arrogó el poder de revisar los actos legislativos y ejecutivos con base en la Sección 2 del artículo III y en la cláusula de supremacía contenida en el artículo V de la Constitución, competencia que fuera extendida a todos los Tribunales en 1816 en sentencia dictada en el caso Martin vs Hunter's Leese, (14 U.S. 1 Wheat 304).

Pero es precisamente el caso norteamericano el primero que ilustra el tema de la competencia para pronunciarse sobre asuntos de constitucionalidad, en el entendido en que tal poder se encuentra limitado por la misma Constitución, donde la Corte Suprema de Justicia conoce exclusivamente de los siguientes asuntos: I. Consultas provenientes de las cortes federales inferiores; II. Apelaciones provenientes de cortes estatales o federales ${ }^{65}$ y III. La con-

${ }^{61}$ Recasens Siches, Luis. Nueva filosofía de la interpretación del derecho. Editorial Porrúa. México.

${ }^{62}$ VON IHERING, (1946).

${ }^{63}$ Recasens Siches, Luis. Nueva filosofía de la interpretación del derecho. Editorial Porrúa. México.

${ }^{64} \mathrm{Al}$ respecto consultar el interesante debate que recoge el profesor Conrado Hübner Mendes titulado "Derechos Fundamentales, separación de poderes y deliberación" (tesis doctoral) de la editorial Saralva, Brasil. 2011.

${ }^{65}$ El recurso de apelación también está restringido a los siguientes casos: A. Cuando una ley estatal ha sido anulada por una Corte Federal de Apelaciones. B. Cuando una ley estatal ha sido declarada constitucional por una Corte Estatal. C. Cuando un tratado federal ha sido declarado inconstitucional en una Corte Estatal. D. En ciertos y muy limitados casos, cuando una Corte Federal de tres jueces ha resuelto el caso en primera instancia. Corte Suprema de los Estados Unidos. 28 U.S.C.A. 1253-1254, 1257. 
cesión de apelaciones provenientes de Cortes inferiores, cuando éstas no son federales, por razones de unificación de jurisprudencia ${ }^{66}$, casos en los cuales la Corte Suprema de Justicia adquiere jurisdicción y decide si formula el conflicto de constitucionalidad, basada en las reglas de asunción de competencia preestablecidas por la misma Corte, como son: a) La necesidad de un caso o "case" ${ }^{67}$, que es lo que se denomina en nuestro sistema como el conflicto o el litigio (Nashville, C \& St. L. R y vs Wallace 288 U.S. 249, 1933); b) La legitimidad o "standing", que se refiere a la posibilidad jurídica de plantear una cuestión de derecho en la que se va a resolver a favor de una de las partes. La Corte ha establecido que, por regla general, los contribuyentes no tienen el derecho a formular cargos de inconstitucionalidad, debido al limitado e indefinido interés que tienen sobre el caso (Frotingham vs Mellon, 262U.S. $447,1923)$; c) La madurez o "ripeness", que indica si el asunto que se somete a revisión es actual, no pudiendo conocer de casos inciertos o eventuales en los que se discuten cuestiones netamente políticas (United Public Workers vs. Mitcheil, 330 U.S. 75, 1975), y d) La litigiosidad o “mootness", que exige que el conflicto (case) aún conserve vigencia y deba ser dirimido por un Tribunal ${ }^{68}$ (De Funis vs Odegaard, 416 U.S. 312, 1974).

Sólo en estos casos la Corte asume competencia y decide si plantea el conflicto de constitucionalidad, para lo cual se observan las reglas establecidas por el Juez Supremo Brandeis en el caso de Ashwander vs. TVA (297 U.S. $288,341,1936)^{69}$.

\footnotetext{
${ }^{66}$ Petition for writ certiorari: Informally called "Cert Petition" A document which a losing party files with the Supreme Court asking the Supreme Court to review the decision of a lower court. It includes a list of the parties, a statement of the facts of the case, the legal questions presented for review, and arguments as to why the Court should grant the writ.

${ }_{67}$ "A" case" requires that caluable legal rights aserted by the plaintiff are threatened by the decision. The question in one lending itself to judicial determination, and the relief sought is a definitive final adjudication of legal rights. Nasville, C. \& St. L. Ry. Vs Wallace, 288 U.S. 249 (1993).

${ }^{68}$ Salvo aquellos casos en los que la Corte decide por la necesidad de sentar un precedente, aun cuando la situación de hecho ha cesado, como cuando se discuten derechos sobre la mujer embarazada a recibir cierto tratamiento médico o a abortar: ciertamente para el tiempo en que el caso es decidido por la Corte, el hecho ya ha sido consumado, lo que no evita el pronunciamiento judicial.
}

${ }^{69}$ A) La Corte no promoverá cuestión de inconstitucionalidad en asuntos no contenciosos o netamente amistosos. B) La cuestión de constitucionalidad no podrá ser anticipada a la necesidad de su decisión. C) La Corte no formulará una regla de derecho constitucional más amplia que la necesaria para resolver el caso bajo estudio. D) La Corte no inaplicará una ley o acto ejecutivo sino en la medida en que el peticionario o reclamante haya demostrado que su aplicación le genera un perjuicio cierto y actual. F) La Corte no revisará la constitucionalidad de una norma, si la parte que la pidió se ha beneficiado de ella 


\subsection{El Derecho Procesal Constitucional en Colombia}

El derecho procesal es una disciplina que se ocupa de estudiar y establecer los procedimientos; el procedimiento es el sistema particular contenido en las leyes y en los códigos; el proceso es la actividad que surge de la pretensión o de la ley y que se sujeta a las leyes de procedimiento ${ }^{70}$. Morales, citando a D'Onofrio, afirma que el derecho procesal estudia aquel sistema de normas que tiene por objeto y fin la realización del derecho objetivo, a través de la tutela del derecho subjetivo, mediante el ejercicio de la función jurisdiccional ${ }^{71}$.

Muchos se preguntan si el derecho procesal constitucional es una rama del derecho y por lo tanto disciplina autónoma. Tradicionalmente el derecho procesal constitucional ha sido estudiado a partir del derecho sustancial constitucional o simplemente como parte del derecho constitucional. Dueñas (2006) afirma que existe un vacío aún no llenado: el de la creación de una teoría procesal propia, pero arriesga poco en la formulación de su propia posición, recordando la consigna sobre la constitucionalización del procedimiento a cambio de procedimentalizar la constitución ${ }^{72}$.

Juan Colombo Campbell, Presidente del Tribunal Constitucional Chileno, define el Derecho Procesal Constitucional como "aquella rama del derecho público que establece las normas procesales orgánicas y funcionales necesarias para dar eficacia real a la normativa constitucional, cuando surja un conflicto entre un acto de la autoridad o de un particular y sus disposiciones". ${ }^{73}$

Para el citado autor esta rama del derecho "comprende la organización y atribuciones de los tribunales constitucionales y la forma en que éstos ejercen su jurisdicción al resolver conflictos constitucionales por medio del proceso y con efectos permanentes" $"$ visión que excluye algunos conceptos que deben ser tratados más a fondo por la doctrina, ya que la Constitución Política ha previsto la preservación de su integridad y supremacía mediante el diseño de

en alguna forma. G) La Corte no podrá revisar estatutos federales, aún si persisten serías dudas sobre su constitucionalidad, si existe una construcción justa del estatuto que permita evitar la cuestión de inconstitucionalidad. En "Constitutional Analysis" de Jerre S. Williams, West Publishing Co. 1979.

70 Oviedo, Amparo. (1995), p. VII.

${ }^{71}$ Morales Molina, Hernando. (1991), p. 15.

72 Dueñas Ruiz, (2006), p. XLI.

${ }_{73}$ Colombo CAmpBelL, Juan, pp. 11-69. http://www.scielo.php?script=S0718-0012200200002\&Ing=es\&nrm=iso. ISSN 0718-0012.

${ }^{74}$ Ibid. 
diversos mecanismos de protección de su articulado como son: i) el control de constitucionalidad dirigido a que la Corte Constitucional excluya del ordenamiento las leyes contrarias a sus dictados, previo el ejercicio ciudadano de la acción pública prevista para tal fin (arts. 241 a 244) ${ }^{75}$; ii) la acción de nulidad por inconstitucionalidad confiada al Consejo de Estado, en virtud de igual ejercicio y con igual objetivo, pero respecto de los decretos dictados por el Gobierno Nacional, cuyo control no ha sido confiado a la Corte Constitucional (art. 237) ${ }^{76}$; iii) el control automático de los decretos legislativos dictados en ejercicio de las facultades conferidas por los artículos 212, 213 y $215^{77}$; iv) la revisión previa de los tratados internacionales y las leyes que los aprueben; v) la inaplicación por parte de todas las autoridades, sin el requisito de previa solicitud, de las leyes o normas que la contrarían (art. $\left.4^{0}\right)^{78}$; vi) la observancia de sus preceptos en todos los campos mediante el imperativo reconocimiento del orden jurídico constitucional en todas las cuestiones de la vida nacional (arts. 6 y 83 a 94 ${ }^{79}$; vii) la inclusión de la Constitución como fuente primaria de las decisiones judiciales (art. 230) ${ }^{80}$; viii) la protección concreta de los derechos fundamentales (arts. 85 y 86$)^{81}$, teniendo en cuenta el bloque de constitucionalidad que da una nueva jerarquía normativa a los tratados internacionales sobre derechos humanos ${ }^{82}$, y ix) la protección judicial de los derechos sociales, económicos y culturales (arts. 88 y 89).

La Corte Constitucional colombiana, con ocasión de la revisión constitucional de la Ley Estatutaria de la Administración de Justicia (Ley No 270 de 1996, modificada por la Ley No 1.285 de 2009) realizada en las sentencias C-037 de 1996 y C-713 de 2008, en relación con los artículos 11 y $43^{83}$, determinó que

\footnotetext{
${ }^{75}$ Consultar entre otras sentencias C-536/98, C-592/98, C-013/00, C-290/00, C-380/00, C-562/00.

${ }^{76}$ Cfr. Sentencias C-513 de 1994 y C-600 de 1998.

77 Respecto del control automático, ver entre otras, las sentencias C-004 y C-579 de 1992, C-179 de 1994 y C-122 de 1999. Sobre la revisión de los tratados internacionales consultar, además, las sentencias C-178 de 1995, C-682 de 1996, C-246 de 1999, C-400 de 1998, C-426 y C-1139 de 2000.

${ }^{78}$ Ver, entre otras, las sentencias C-434 y 479 de 1992, C-281 de 1994, C-069 de 1995, C-037 de 1996, C-600 de 1998 y T-522 de 2001.

${ }^{79}$ Consultar, además, las sentencias C-176 de 1994 y SU de 1997.

${ }^{80} \mathrm{Al}$ respecto, además, las sentencias C-486 de 1993, T-296, T-505 y C-588 de 1994, T-294 de 1995.

${ }^{81}$ Corte Constitucional, sentencia C-739 de 2001.

${ }^{82}$ Fix Zamudio, Héctor. (2001).

${ }^{83}$ Que definieron los órganos de la jurisdicción constitucional.
} 
integran la Jurisdicción Constitucional, además de la Corte y del Consejo de Estado, los jueces y corporaciones judiciales, en cuanto les corresponde aplicar los preceptos constitucionales a cada caso concreto, distinguiendo lo que debe entenderse por jurisdicción y por control constitucional, bajo el punto de vista funcional y orgánico, por cuanto consideró que no todas las autoridades que ejercen dicho control integran la jurisdicción constitucional, pero que esta circunstancia no implica que en Colombia la defensa de la Constitución Política se haya concentrado sólo en los integrantes de esa jurisdicción.

Así, con la expedición de la nueva Constitución y la inclusión de mecanismos de protección inmediata de los derechos constitucionales en los artículos 86 y 88 , así como la consagrada en el artículo 241 , se promulgaron leyes de contenido eminentemente procedimental, tales como los decretos $\mathrm{N}^{\circ}$ s. 2.591 de $1991^{84}$, 2.067 de $1991^{85}$, 306 de 1992, la Ley No 472 de 1998 y la Ley No 1.095 de 2006 , donde se regularon aspectos procesales, generales y particulares, para la defensa de los derechos e intereses individuales y colectivos, protegidos por la Carta.

En cada uno de ellos se incluyen reglas relativas al ejercicio de las acciones, la jurisdicción, la competencia, la legitimación, las partes, los sujetos procesales, el juez, la caducidad, los principios rectores, las medidas cautelares, las nulidades, la sentencia y sus efectos, los mecanismos para hacerla cumplir, los poderes del juez y, en general, los aspectos relativos al procedimiento y al proceso constitucional.

Asimismo, en cada uno de estos cuerpos legislativos se incluyeron normas de reenvío y normas supletorias para la aplicación de procedimientos insertos en el Código de Procedimiento Civil y el Código de Procedimiento Penal, los cuales, mutatis mutandis, regulan aspectos no contemplados en la respectiva legislación procedimental constitucional.

J.J. Monroy Palacios, al comentar sobre José Joaquín Gomes en su escrito Canotilho Constituição e dèfice procedimental, publicado en "Estados sobre direitos fundamentais", Coimbra 2004, pp. 69-84, afirma: "particularmente, en el valor metodológico que le asigna al concepto status activus processualis, pergeñado en los años 70 por Häberle (Grundrechte im Leistungstaat, VVDSTRL, No 30, 1972), por medio del cual no es posible siquiera hablar de una adecuada

${ }^{84}$ Ver entre otras las sentencias: C-018 de 1993, C-531 de 1993, C-054 de 1993, C-134 de 1994, C-092 de 1997, C-1716 de 2000.

85 Ver las sentencias: C-513 de 1992, C-105 de 1993, C-113 de 1993, C-131 de 1993. 
tutela de los derechos fundamentales si no se reconoce, en los miembros de la comunidad, el derecho a participar en el proceso con todas las garantías que ello supone", y valiéndose de lo expresado por el profesor alemán, Gomes Canotillo sostiene que "la participación en el procedimiento de decisión constituye, de forma inmediata, una posición subjetiva inherente al derecho fundamental. En otras palabras: la participación procedimental es, ella misma, el ejercicio de un derecho fundamental", de manera que "el ciudadano, al poseer instrumentos jurídico-procesales que posibiliten una influencia directa en el ejercicio de las decisiones de los poderes públicos que afectan o pueden afectar sus derechos, garantiza a si mismo un espacio de real libertad y de efectiva autodeterminación en el desenvolvimiento de su personalidad" (p. 73).

Para utilizar con propiedad las categorías ajenas a su especialidad, el autor se vale de Comogolio y Dinamarco, dos de los más prestigiosos procesalistas contemporáneos; sin embargo, al encarar el contenido propio del status activus processualis, retorna a la doctrina alemana, en particular hace sustancialmente suyos los postulados de Helmut Goerlich (Grundrechte als Verfahrensgarantie, Baden - Baden, 1981) para quien "la existencia de un derecho subjetivo en el procedimiento /proceso" implica que "cualquier derecho material postula una dimensión procedimental/procesaly, por esto, reconocer un derecho material constitucional implica necesariamente reconocer un derecho subjetivo del procedimientol proceso indispensable para garantizar la eficacia del derecho material'(p. 78).

Esto significa, en otros términos, que cualquier derecho fundamental consagrado por el ordenamiento exige la configuración de un remedio procesal idóneo para su adecuada protección, dando lugar a un derecho subjetivo del ciudadano que se corresponde con un deber -en el sentido de "crear", "asegurar"- por parte del Estado (correlación que el profesor portugués no llega a aceptar del todo, pues si bien reconoce la tarea pendiente del Estado, duda de los alcances del derecho subjetivo del particular)" 86.

Colombo Campbell, apoyado en Kelsen, Calamandrei, Cappeletti, Favoreu, Fix-Zamudio, Cotoure, Pedro Sagüés, Brewer-Carías, Niceto Alcalá Zamora y Rodolfo Pisa ${ }^{87}$, afirman que el Derecho Procesal Constitucional es aquella

\footnotetext{
${ }^{86}$ J.J. Monroy Palacios. http://derechoyproceso.blogspot.com/2008/02/constitucin-y-dficit-procedimental. html.

${ }^{87}$ Otros exponentes del Derecho Procesal Constitucional son Domingo García Belaunde, Mauro Capelleti, Germán J. Brigart Campos, Héctor Fix-Zamudio, Néstor Pedro Sagües, Rubén Gonzalez Valle, José Humberto Nogueira Alcalá, Giancarlo Rolla, Javier Henao Hidrón, Ernesto Rey Cantor, José Palomino Manchego, Eduardo Esteva, Eduardo Ferrer McGregor Poisot, Aníbal Quiroga León, Óscar Puchineli,
} 
ciencia que estudia la Justicia Constitucional, a partir de tres grandes áreas temáticas: 1. El conflicto constitucional y sus formas de solución; 2. El Derecho Procesal Constitucional orgánico, y 3. El Derecho Procesal Constitucional funcional.

Es claro que, a partir del reconocimiento de la existencia de los procedimientos constitucionales, impera la necesidad de formular nuevas teorías en el marco de una ciencia que, como la procesal civil, la procesal penal, inclusive la procesal administrativa, se encarga de estudiar un conjunto de procedimientos encaminados a la protección y materialización de los derechos sustantivos consagrados en la Constitución ${ }^{88}$.

\section{El control judicial constitucional a la luz del derecho comparado}

La ley fundamental alemana (Grundgesetz o GG) dispone en su artículo 20 que "el poder legislativo está sujeto al orden constitucional; los poderes ejecutivo y judicial están sujetos a la Ley y al derecho". Con base en este artículo, el derecho alemán ha introducido nuevos conceptos para judicializar el estudio de la Constitución; son estos la "Normprüfung" y la "Normverwerfung". La primera, "examen de la ley", corresponde a todos los jueces del Estado, en que cada uno de ellos se encuentra facultado para iniciar el estudio de las normas a partir de la Constitución y en comparación con ella; y la segunda, el "rechazo de la ley", se encuentra deferida al Tribunal Constitucional que conoce de forma exclusiva sobre su estudio, de manera que, en la actualidad, el sistema de remoción se encuentra estatuido como sistema incidental: cuando el juez inferior, en uso de la "Normprüfung", se encuentre frente a una nueva incompatibilidad, dará noticia al Tribunal Constitucional para que este, en uso de la "Normverwerfung", retire la norma del ordenamiento ${ }^{89}$.

Alfredo Gozaini, Víctor Bazán, Ernesto Jorge Blume Fortini, Humberto de la Roche, Allan Randolf BrewerCarías, Alfonso Noriega, Eloy Espinoza-Saldaña y Barrera, Boris Barrios González, Francisco Fernández Segado, Juan Carlos Hitters, Iván Escobar Fornos, María Sofía Sagüés, Gabriela Ávalos, Sebastián Franco, Anita Giacomette Ferrer, Hernán Olano y Diego López Medina.

${ }^{88}$ Olano (2005), apoyado en Sagüés, afirma que el Derecho Procesal Constitucional es una disciplina mixta, que hace parte del derecho constitucional y a la vez del procesal. Olano, Hernán Alejandro. "El Derecho Procesal Constitucional". Revista Universitas No 109.

${ }^{89}$ Ley Fundamental de la República Federal alemana, mayo 23 de 1945. Art. 100: “Inconstitucionalidad de las leyes. Si un Tribunal considera que una ley de cuya validez depende su decisión es inconstitucional, deberá suspender el proceso y someter la cuestión a la decisión del Tribunal competente para conocer de los litigios constitucionales del Land, si se trata de infracción de la Constitución de un Land (Estado), o a la 
El Tribunal Constitucional (“Bundesverfassungsgericht") ${ }^{90}$ conserva el monopolio del control negativo y la facultad de defensa de los derechos constitucionales, pero ese monopolio se entiende exclusivamente sobre los actos del Congreso que impliquen la expedición de una Ley (Verwerfungsmonopol); todo acto supralegislativo, es decir, decretos, reglamentos y en general todo acto no formal emanado del cuerpo legislativo o cualquier otra autoridad quedará por fuera de la esfera del Tribunal Constitucional ${ }^{91}$. En la actualidad el Tribunal ha extendido su competencia para aquellas leyes expedidas con anterioridad a la GG, con base en una supuesta voluntad del legislador de mantener vigente la norma anterior, que legitima al Tribunal para conocer de su constitucionalidad por estar provistas de una presunción de validez legislativa por su tácito reconocimiento de las normas supra-constitucionales al no ejercer su potestad de retirarlas del ordenamiento por la vía de derogatoria expresa.

En Francia, la empresa tuvo origen en la misma Constitución. En 1852, la Carta fundamental de Napoleón III facultaba al Senado para oponerse a las leyes inconstitucionales hasta antes de su promulgación; entre 1894 y 1903 fueron presentados proyectos ante el Congreso en el sentido de crear un alto Tribunal que conociera de los recursos elevados por los ciudadanos cuando una ley desconociera sus derechos constitucionales; de este modo se proponía la creación de una jurisdicción constitucional con facultades para velar por la protección de los derechos ciudadanos.

Tanto el Consejo de Estado como la alta corte se encargaron de avalar esta posición y la propuesta tampoco tuvo eco en el parlamento francés. La Constitución no dotó al poder judicial de jurisdicción para conocer de los recursos presentados en contra de las normas por violar la Carta y es por ello que los altos Tribunales adoptaron una posición rígida al respecto: si la Constitución no faculta al poder jurisdiccional para invalidar los actos del Congreso, no serían ellos los llamados a ejercer control en su nombre. Sin embargo, la doctrina francesa no descansaría hasta lograr plasmar algún tipo de control constitu-

decisión del Tribunal Federal, si se trata de la violación de esta Ley fundamental. Lo mismo vale en caso de violación de esta Ley Fundamental por el derecho de un Land de incompatibilidad entre una Ley de un Land y una Ley federal'.

${ }^{90}$ Sobre la naturaleza del Bundesverfassungsgericht como órgano constitucional supremo (superiorem non recognoscens), ver PHOLE, R., Verfassungsbeschwerde und Zivilprozess in Bayern, en Beiträge zum Zivilprozesrecht. Festgable zum 70 Geburtstag von Leo Rosemberg, München 1949.

${ }^{91}$ Prada Tamayo, Alejandro Mauricio. "El control incidental de validez". En Revista de Derecho Público No 7. Universidad de los Andes. Febrero de 1997, p. 62. 
cional; autores como André Blondel ${ }^{92}$, Haouriou ${ }^{93}$ y Bordeau, pregonaron la necesidad de poner freno a la actividad desbordada del Senado y limitar el poder del emperador para influenciar sobre el cuerpo legislativo en la expedición de leyes inconstitucionales.

Como resultado de este clamor la Constitución introdujo un nuevo órgano de control, de naturaleza, más que jurídica, política, llamado Comité Constitucional, que según el artículo 92 (par. 3) era competente para "[...] resolver sobre la posibilidad de revisar las disposiciones de los títulos I a X de la Constitución examina si las leyes votadas por la Asamblea Nacional supone una revisión de la Constitución”. En 1958, la Constitución atribuyó nuevas facultades al Consejo Constitucional, en las cuales se incluían el control de la legitimidad de las elecciones parlamentarias y del Presidente de la República, los referendum, leyes y reglamentos parlamentarios y una función consultiva en materia de decretos expedidos en función de medidas exceptivas. Sin embargo, la actuación del Consejo quedó relegada a la petición elevada por el Presidente de la República, el Presidente del Consejo o el Presidente de las Cámaras, lo que excluyó de plano la posibilidad para los ciudadanos corrientes de acceder al control constitucional.

En Italia, la "Costituzione della Repubblica" dispuso de un artículo especial, que regula el ejercicio de la jurisdicción constitucional ${ }^{94} \mathrm{y}$ ordenó la emisión de una Ley Constitucional que estableciera los parámetros en que se debe realizar el juicio de legitimidad para las leyes, definiendo la regulación de todas las demás funciones de la Corte y los asuntos constitucionales a una Ley Ordinaria. En 1948 se emitió la Ley Constitucional número 1 que reglamentó el artículo 134 y en 1953 fue promulgada la Ley Ordinaria número 87, que regulaba el ejercicio de las cuestiones de legitimidad constitucional, reglamentando así el artículo $137^{95}$.

92 Blondel, André. (1928).

${ }^{93}$ Hauriou, André. (1971).

${ }^{94}$ Art. 134: "La Corte Constitucional juzga: Sobre las controversias relativas a la legitimidad constitucional de las leyes y de los actos con fuerza de ley, del Estado o de las regiones".

${ }^{55}$ La historia constitucional italiana remonta el nacimiento de las "leyes constitucionales" a 1928. Los cuatro períodos en que se divide la historia constitucional italiana muestran cómo evolucionó la institución hasta lograr espacio definitivo en la Constitución actual. Son estos: El primero, desde 1861 (17 de marzo) hasta el 28 de octubre de 1922, época del fascismo; en él, el sistema se caracterizaba por la intervención legislativa conjunta del Jefe de Estado y el Legislativo, de modo que el rigor no era precisamente tema de las deliberaciones constitucionales. El segundo período correspondió al imperio 
A primera vista se evidencia la flexibilidad del sistema italiano. Mientras en países como Alemania, Suiza y España, se requiere un pleno convencimiento del Juez de que los motivos que fundan la cuestión están suficientemente probados por quien la invoca, es decir, se requiere de un serio juicio que genere incertidumbre en el funcionario para que se plantee la cuestión de constitucionalidad, en la legislación italiana bastará con que no se "advierta que la cuestión es manifiestamente carente de fundamento ${ }^{\times 6}$.

La ley constitucional número 1 de 1948 comprende dos sistemas de control, activo y exceptivo. El primero se ejerce ante la Corte Constitucional, a petición del Gobierno, cuando una ley de una región exceda su competencia o resulte inconveniente con el interés nacional. El segundo faculta las regiones para postular la invalidez, cuando una ley general de la República afecte o invada su esfera de competencia; en este caso podrá acudir ante la Corte Constitucional la Región interesada, para plantear la cuestión de legitimidad; y por último, una región podrá impugnar la legitimidad de una ley de otra región cuando ésta invada su esfera de competencia. En los demás casos, la cuestión deberá ser planteada por vía incidental, en el caso individual, probando legitimidad, y sometiendo a juicio del Juez la decisión sobre los fundamentos de la impugnación.

En este evento la cuestión también puede ser propuesta de oficio y se seguirá la actuación a la Corte Constitucional para que esta decida definitivamente sobre la cuestión de ilegitimidad y se pronuncie sobre la aplicabilidad de la norma.

Suiza por su parte, ha establecido mecanismos que se asemejan a un control posterior y difuso de constitucionalidad. En el artículo 113 de la derogada Constitución de 1874, se facultaba a los ciudadanos de los cantones para ejercer un recurso de inconstitucionalidad sobre actos cantonales, pero tal aptitud no se extendía a los actos federales, los cuales se encontraban resguardados de cualquier control por parte del poder judicial ${ }^{97}$.

fascista y sólo en el tercero, 1928, se logró la institucionalización de las leyes constitucionales en contraposición a las leyes ordinarias, hecho que marcó hito en el sistema de control de la Constitución, pues la institución perduró hasta la caída del régimen totalitario con la expedición de la Carta de 1946. La creación de las leyes constitucionales justificó e hizo necesaria la creación de métodos para ejercer control sobre la Constitución. Óscar Vásquez del Mercado. Op. Cit., p. 68.

${ }^{96}$ Prada Tamayo, Alejandro Mauricio. (1997), p. 63.

97 "A la Corte Federal se le adjudica: 1. Conflictos de competencia entre autoridades federales por una parte y autoridades de los cantones por la otra; 2. Disputas entre los cantones en el campo del derecho público; 3. Las quejas concernientes a la violación de los derechos constitucionales de los ciudadanos asi como las quejas indi- 
El requisito primordial para que una persona pudiera invocar una cuestión de inconstitucionalidad ante la autoridad era que actualmente sufriera un daño subjetivo como consecuencia de la aplicación de una norma y que se encontrara legitimado procesalmente para ejercer la petición ${ }^{98}$.

El derecho constitucional suizo consagraba entonces una serie de protecciones en la Carta Fundamental que debían ser consultadas para estimar la viabilidad del recurso. Con todo, la práctica llevó a convertirlo en un medio subsidiario, toda vez que el Tribunal Federal estableció límites para ejercer el derecho: en tanto y en cuanto existiesen otros medios judiciales para lograr la protección efectiva de un derecho, la justicia constitucional se abstendría de conocer de su infracción ${ }^{99}$.

La legitimación para recurrir variaba según el derecho lesionado. Si se trataba de un derecho subjetivo y personal, sólo podría alegarlo quien habría sufrido efectivamente la lesión. Pero, en cambio, si se trataba de un derecho público, como el acceso a la justicia o al voto, se podía invocar la cuestión con carácter preventivo y estaba legitimada cualquier persona que se sintiera afectada por la Ley. Con todo, se debía observar siempre de qué tipo de ley se trataba, pues como ya se anotó, no podían ser acusadas normas de tipo federal.

La "Constitución Federal Suiza" del 18 de abril de $1999^{100}$, tercera constitución federal, estableció a la "Confederación Suiza" como una República de 26 cantones o estados. Contiene un catálogo de derechos individuales y populares, incluyendo el derecho a convocar referendos populares sobre leyes federales y enmiendas constitucionales y creó un nuevo cuerpo judicial denominado Corte Suprema de Justicia Federal, cuyas funciones se encuentran establecidas en el capítulo 4:13, artículos 188 y siguientes, entre otras, las de resolver las disputas

viduales relativas a la violación de concordatos y tratados internacionales; 4. Se reservan las disputas administrativas para ser determinadas por la legislación federal; 5. En todas las instancias anteriores la Corte deberá recurrir a las leyes en general decretos obligatorios adoptados por la Asamblea Federal, asi como los Tratados internacionales aprobados por ella".

${ }^{98}$ Idéntico requisito exigido por la doctrina norteamericana para la proposición de la cuestión de inconstitucionalidad.

${ }^{99}$ Cappelletti, Mauro. Op. cit., p. 166.

${ }^{100}$ Adoptada en la votación de marzo 12 de 2000, certificada por la decisión del gobierno federal de mayo 17 de 2000 y basada en el Decreto Federal del 8 de octubre de 1999. Publicada en sus idiomas oficiales: Alemán: Bundesverfassung der Schweizarischen Eidgenossenschaft; Francés: Constitution federale de la Confederation suisse; Italiano: Constituzione federale della Confederazione Svizzera; Romance: Constituzium federala da la Confederazium sviza. 
entre los cantones, la protección de los derechos federales y la protección del derecho internacional.

En España, la cuestión ha sido manejada en una perspectiva similar a la italiana. Los jueces se encuentran facultados para plantear ante el Tribunal Constitucional la cuestión de inconstitucionalidad, cuando resulte manifiesta la violación por una norma, de un precepto superior, y tal norma sea necesaria para resolver el caso del que se esté conociendo. El control es puramente judicial, al igual que en los demás países estudiados. A diferencia del caso de todos ellos, la norma que otorga tal poder se encuentra perfectamente delimitada en la Constitución, de modo que la labor de interpretación no ha tenido mayores tropiezos.

Sin embargo, esta situación expresa no siempre tuvo el mismo matiz. Históricamente España se consagró como terreno de permanentes revoluciones ideológicas que enriquecieron la teoría constitucional; las permanentes luchas internas y el deseo de dotar a sus legislaciones de garantías efectivas para el respeto de los derechos instituidos en las distintas constituciones, tuvieron eco finalmente en la Constitución de 1978.

La Constitución española ha definido con claridad el asunto de la inconstitucionalidad de la ley en su artículo 163, en el cual ha establecido los requisitos y finalidades del recurso ante el Tribunal Constitucional, cuando un juez advierta en el curso de un proceso que se debe someter a estudio de legitimidad constitucional la norma encargada de dirimir un conflicto en concreto y por otra parte prevé un Recurso de Amparo en los casos en que una autoridad vulnere de manera subjetiva un derecho consagrado en la Constitución.

El derecho comunitario europeo, ratificado por el tratado de la Unión en Maastricht el 7 de febrero de 1992, estableció un sistema de colaboración judicial armónica, en el que los jueces de cada Estado han quedado facultados para dar aviso a sus altas Cortes, con el fin de que ellas, a su vez, planteen las cuestiones que surjan con mérito de la aplicación de leyes internas contrarias al Derecho Comunitario, ante el Tribunal de Justicia de las comunidades europeas.

El tratado de Maastricht prevé dos tipos de controles, uno es el que corresponde a la Corte por vía de interpretación y otro el que se le atribuye por vía incidental, de validez, teniendo a su vez, cada uno, origen en sistemas constitucionales diferentes. El control de interpretación proviene de Francia ${ }^{101}$.

${ }^{101}$ Prada Tamayo. Op. cit., p. 55. 
En México debido a que la Corte Suprema de Justicia de la Nación se ha convertido en un Tribunal Constitucional a partir de la reforma constitucional de 31 de diciembre de 1994, al conocer, además del centenario juicio de amparo en última instancia, también de las acciones de inconstitucionalidad (control abstracto) y de las controversias constitucionales, teniendo sus resoluciones efectos generales para el futuro en algunos apócrifos. Fundamentalmente a través de las controversias constitucionales se desarrolla la tendencia de la judicialización de las cuestiones políticas, que tiene una importante realización por conducto de la interpretación constitucional, como lo expresa Fix Zamudio ${ }^{102}$.

\section{Jurisdicción Constitucional en Colombia}

El concepto general de jurisdicción se ha definido tradicionalmente como "la función pública de hacer justicia" ${ }^{103}$. El vocablo jurisdicción, como lo anotan los estudios del derecho procesal ${ }^{104}$ significa "poder o autoridad que se tiene para gobernar y poner en ejecución las leyes o para aplicarlas en juicio" 105 , y etimológicamente significa declarar, expresar el derecho, de los vocablos latinos iuris (justo, de derecho, jurídico) y dictio (dicción, expresión, sentencia o fallo).

Todo sistema de Control Constitucional se fundamenta en la Jurisdicción, bien sea especial u ordinaria, encargada de velar por la supremacía de las normas superiores. Es por ello que en Colombia se estableció en 1991, al amparo de los artículos 86, 88, 116, 237 y 241 de la Constitución, una jurisdicción autónoma denominada "Constitucional", de la cual hacen parte, en sentido orgánico, la Corte Constitucional y el Consejo de Estado y en sentido funcional los jueces y corporaciones que deban proferir las decisiones de tutela o resolver acciones o recursos previstos para la aplicación de los derechos constitucionales (Corte Constitucional, C-713 de 2008).

En sentencia T-006 de 1992, la Corte Constitucional, al definir la jurisdicción constitucional, determinó que, además de la Corte Constitucional, los jueces de la República también hacen parte de ella:

\footnotetext{
${ }^{102}$ Fix Zamudio, Héctor, ( 2000), pp. 557-591.

${ }^{103}$ Couture, Eduardo J. (1966), p. 28.

${ }_{104} \mathrm{Al}$ respecto consúltese las obras de Hernando Devis Echandía en sus Nociones Generales de Derecho Procesal Civil, Hernando Morales Molina en su Curso de Derecho Procesal Civil parte General y Jairo Parra Quijano en su Derecho Procesal Civil parte General Tomo I.

${ }^{105}$ Real Academia de la Lengua Española. Diccionario de La Lengua Española. Ed. Espasa Calpe. Vigésima Primera Edición. Madrid, 1992. Tomo II, p. 1215.
} 
"La jurisdicción constitucional, bien comprendido su objeto, debe entenderse en sentido material, máxime si se tiene en cuenta que las competencias específicas sobre el particular no se radican en un único órgano judicial. (...) El artículo 241 de la Constitución Política confía a la Corte Constitucional la guarda de la integridad y supremacía de la Constitución y enumera los asuntos de constitucionalidad sobre los cuales debe pronunciarse. El artículo 237 de la Constitución Política atribuye al Consejo de Estado el conocimiento de las acciones de nulidad por inconstitucionalidad de los decretos dictados por el Gobierno Nacional, cuya competencia no corresponda a la Corte Constitucional. De otra parte, según la misma norma, como Tribunal Supremo de lo Contencioso Administrativo, conforme a las reglas que señale la ley, le corresponde pronunciarse sobre la constitucionalidad de la actuación administrativa. De conformidad con el artículo 86 de la Constitución Política, toda persona tendrá acción para reclamar ante los jueces la protección inmediata de sus derechos constitucionales fundamentales".

Según lo anterior, hacen parte de la Jurisdicción Constitucional: En sentido orgánico: a) La Corte Constitucional, suprema autoridad y órgano de cierre de la Jurisdicción (C.P. art. 241), y b) El Consejo de Estado, cuando resuelve las acciones de nulidad por inconstitucionalidad (C.P. art. 237). En sentido funcional: Todos los jueces de la República, incluidos el Consejo de Estado, la Corte Suprema de Justicia y el Consejo Superior de la Judicatura, cuando resuelven: a. Acciones de tutela (C.P. art. 86); b. Acciones populares (C.P. art. 88), y c. El recurso de Habeas Corpus (C.P. art. 30).

No hacen parte de la Jurisdicción Constitucional, por expresa disposición del artículo 86 de la Constitución o bien de la ley: Los jueces de paz ${ }^{106}$; el Congreso de la República en función jurisdiccional ${ }^{107}$; los fiscales de la República ${ }^{108}$; los particulares cuando administran justicia en calidad de árbitros o de conciliadores ${ }^{109}$; los superintendentes cuando cumplen funciones

\footnotetext{
${ }^{106}$ Ley No 497 de 1999, art. 9o. D.O. No 43.499, de 11 de febrero de 1999.

107 La atribución jurisdiccional del Congreso se limita al juzgamiento de los funcionarios que gozan de fuero constitucional y por lo tanto no se extiende a los demás administrados.

108 Aunque los fiscales de la República en efecto ejercen jurisdicción en determinados asuntos (SC 1194-05) la competencia para conocer de las acciones constitucionales está radicada exclusivamente en "los jueces" (arts. 86, 87 y 88 de la C.N.) y en tal virtud no integran la Jurisdicción Constitucional.

109 En la medida en que los conciliadores y los árbitros conocen de asuntos de naturaleza transigible, la cual no se predica de los derechos constitucionales. Corte Constitucional, Auto 070/99 y Sentencia T-677-01.
} 
jurisdiccionales; las autoridades indígenas ${ }^{110}$; los jueces penales militares ${ }^{111}$; las demás personas y autoridades que ejercen jurisdicción de manera transitoria, salvo el caso de los conjueces, quienes por expreso mandato de la Ley Estatutaria de la Administración de Justicia, ejercen plena jurisdicción en los casos a ellos encomendados, en la misma forma en que lo hacen los jueces a quienes reemplazan.

La integración funcional de la jurisdicción constitucional obedece a un concepto de transitoriedad, en la medida en que cada uno de los jueces que conocen de las acciones que protegen derechos constitucionales, orgánicamente integran distintas jurisdicciones como la Ordinaria, la Contencioso Administrativa o la Disciplinaria.

Así, por ejemplo, un Juez Civil del Circuito, que orgánicamente integra la Jurisdicción Ordinaria, conoce de una acción de reivindicación del dominio o de un proceso ejecutivo o de un proceso de restitución de inmueble, de linaje estrictamente civil, al resolver no hace parte de la jurisdicción constitucional, pero, si a su conocimiento se somete por la vía de la Acción de Tutela una solicitud de amparo de un derecho fundamental, como puede ser la vida, la libertad personal o el debido proceso, resuelve como Juez Constitucional y en tal medida, por razón de sus funciones, integra la Jurisdicción Constitucional, caso en el cual sus superiores funcionales jerárquicos serán, en su orden, un Tribunal Superior de Distrito Judicial y la Corte Constitucional, mientras que en el primer caso, en la acción civil, sus superiores serán el Tribunal Superior de Distrito Judicial y la Corte Suprema de Justicia, esta última como máximo órgano y tribunal de cierre de la Jurisdicción Ordinaria.

Lo propio ocurre en cada una de las jurisdicciones, bien sea la Contencioso Administrativa, compuesta por tres órganos permanentes y uno funcional, siendo los primeros los jueces, los tribunales y el Consejo de Estado y la última la Corte Suprema de Justicia (cuando resuelve asuntos contra el Consejo de Estado o sus Consejeros) o la Disciplinaria, integrada por el Consejo Superior de la Judicatura y los Consejos Seccionales de la Judicatura.

\footnotetext{
${ }^{110} \mathrm{Su}$ actuación no se adecua a las prescripciones del derecho interno.

111 "La acción de tutela escapa el conocimiento de la justicia penal militar. Sostener lo contrario implicaría violar la Constitución por uno de estos dos aspectos: o por someter a los civiles a la investigación y el juzgamiento de la justicia penal militar (artículo 213, inciso final), o por ampliar el ámbito de ésta a asuntos que no le están asignados por la Constitución (artículo 221)". Corte Constitucional, Auto 012 de 1994.
} 
Ahora, es necesario aclarar que todo juez podrá conocer de procesos contenciosos subjetivos de constitucionalidad (Art. 86 C.N., Decreto No 2.591 de 1991, Ley No 472 de 1998, Ley No 270 de 1996 y Ley No 1.095 de 2006), pero no todos podrán conocer de procesos contenciosos objetivos, ya que tal posibilidad le está reservada a la Corte Constitucional y al Consejo de Estado por expreso mandato de los artículos 237 y 241 de la Constitución, reglamentados por los Decretos No 01 de 1984 y No 2.067 de 1991 y la recientemente expedida Ley No 1.437 de 2011.

\section{Funciones del Derecho Procesal Constitucional frente a la Jurisdicción Constitucional}

Corresponde a la Ciencia Jurídica Procesal definir las condiciones en las cuales el constituyente y el legislador dotan al juez de poderes especiales para la guarda de la integridad y la supremacía de la Constitución, bajo el supuesto de que es al juez constitucional al que se le encarga, a diferencia de los jueces ordinarios, dos funciones fundamentales, como son: a) La aplicación directa de la Constitución (en función guardiana) y b) La interpretación de la Constitución.

En tal medida, ha correspondido al Derecho Procesal Constitucional definir la forma como deben ser ejercidas estas funciones, mediante la solución de los grandes interrogantes que se plantean frente al ejercicio de la jurisdicción constitucional, como son: a) Debe ser un solo juez, concentrado y superior, quien aplique la Constitución; b) Puede encargarse la labor interpretativa a varios jueces de manera difusa; c) Hasta dónde llega el poder interpretativo del juez; cuál es la naturaleza de un Tribunal Constitucional; d) Es suficiente un control objetivo de la Constitución o se justifica un control concreto para casos particulares; e) Puede el juez constitucional suplir la inactividad del órgano legislativo cuando éste incumple su deber de legislar conforme a la Constitución; f) Puede el juez constitucional suplir la inactividad del poder ejecutivo cuando éste incumple su deber de realizar la Constitución; g) Están supeditados los demás jueces de la República al Juez Constitucional; h) Existe, en efecto, una Jurisdicción Constitucional o una o varias jurisdicciones ordinarias dentro de las cuales se ejerce control constitucional; i) Cuáles conflictos tienen relevancia o pertinencia constitucionales.

\section{Consideraciones en torno al control constitucional por la vía exceptiva}

El Derecho Procesal Constitucional también se ocupa de estudiar los procedimientos por los cuales se protege la Constitución por vía exceptiva. Sin 
embargo es necesario aclarar que el procedimiento para aplicar una excepción de inconstitucionalidad no se encuentra regulado en estatutos especiales, sino en las reglas que rigen para cada uno de los procesos judiciales, administrativos y aún constitucionales, sean estos contenciosos o no, pues hace parte del control difuso de constitucionalidad.

Históricamente el caso norteamericano ha sido tomado como punto de partida del control incidental de validez de los actos. El caso "Marbury v. Madison", que marcó un precedente en el sistema constitucional moderno, ha sido tomado como referencia para la elaboración teórica y jurídica de las instituciones de control que vendrían a reforzar los regímenes constitucionales en Europa, y posteriormente en los estados latinoamericanos a partir del siglo XIX.

El control difuso ha tenido vigencia en Colombia desde comienzos de siglo, cuando en la reforma constitucional de 1910 los diputados a la Asamblea Constituyente decidieron dotar definitivamente a la Constitución de herramientas judiciales que impusieran límites a la actividad de las demás ramas del poder público, como producto de esa rígida división tripartita planteada en Europa con la teoría clásica de Montesquieu ${ }^{112}$, en la que las cargas de cada una de ellas se contraponían para crear sistemas autónomos de división interna de Estado.

La excepción de inconstitucionalidad es una institución, que, a diferencia de otras como la Acción de Tutela, la Acción Pública de Inconstitucionalidad, las acciones populares, se debe proponer en el transcurso de un proceso, bien sea de naturaleza judicial o administrativo, por su naturaleza eminentemente incidental, lo que no implica, como bien lo anotara el Consejo de Estado en su momento, que se trate de una herramienta procesal propia de los sistemas tradicionales y en cabeza de un demandado en el transcurso de un proceso; quiere decir que se requiere de la existencia de un funcionario y de un proceso en curso para invocar la petición, razón por la cual deberá ser propuesta durante una actuación, judicial o administrativa y en tal medida corresponde al Derecho Procesal, General y Constitucional, estudiar la forma como debe ser aplicada, pues la institución comporta una doble naturaleza, objetiva y subjetiva, ya que, para declararla se requiere de un proceso judicial en curso (aspecto subjetivo), pero el análisis será, en todos los casos, eminentemente objetivo.

${ }^{112}$ Montesquieu, Charles de Secondat (1933). 


\section{El derecho procesal constitucional y el derecho probatorio constitucional como disciplinas autónomas}

A lo largo del estudio se ha demostrado que el Derecho Procesal Constitucional es una rama independiente del derecho ${ }^{113} \mathrm{y}$, como disciplina autónoma, se encarga de estudiar procedimientos que regulan aspectos objetivos y subjetivos del control de constitucionalidad, a partir de la creación de sistemas de solución de controversias y por medio de autoridades que integran las distintas ramas del poder público.

Se determinó también que existen actuaciones reguladas íntegramente por la Constitución, bien sean estas contenciosas o no contenciosas, y que, como parte de la actividad pública, se enmarcan en procedimientos especiales de obligatorio cumplimiento, en cuyo marco se desarrollan aspectos de relevancia y pertinencia constitucionales y en tal medida se justifica estudiarlos bajo una perspectiva que permita formular verdaderas teorías que incorporen los principios y los valores de rango superior.

Si el derecho es ciencia, y como tal le corresponde armonizar los conceptos en virtud de los cuales se crean sistemas normativos, entonces le corresponde al Derecho Procesal Constitucional estudiar el conjunto de principios que priman en el sistema de protección de las normas consagradas en la Constitución, a partir del sistema jurisdiccional, el cual se encarga a su vez de velar por el cumplimiento de tales normas, mediante la creación de órganos investidos de poderes especiales, con facultades de ordenación, de instrucción y de imperio.

Esta conclusión, sin embargo, no se extiende al derecho probatorio, pues si bien se advierte que no existe una transversalidad en las normas que regulan la actividad probatoria, aún no se define cómo, ni bajo qué reglas o paradigmas específicos, han de estudiarse tales normas.

\section{Conclusiones}

La investigación permitió resolver los interrogantes planteados en torno a los problemas formulados, así:

\subsection{La litigiosidad en la protección de los derechos constitucionales}

Se concluyó que la Constitución establece dos tipos o clases de procesos, según intervenga o no un juez. El primero, identificado como "procedimiento

${ }^{113}$ Ferrer Mac-Gregor, Eduardo. (2008). 
constitucional, tiende a desarrollar las disposiciones orgánicas, es decir, aquél que propende por la integración de los poderes, la expedición de la ley o la integración de los órganos constituidos. El segundo, aquel que busca la protección o salvaguarda de la Constitución por violación objetiva o subjetiva. A éste se le denomina "proceso constitucional".

El proceso constitucional, también definido como "contencioso" o "litigioso", es aquel que se surte ante un juez, en este caso un juez constitucional, y puede, según su pretensión, clasificarse en "objetivo" y "subjetivo".

El proceso contencioso objetivo, público o popular de anulación por inconstitucionalidad, es aquel dirigido contra actos impersonales y abstractos, cuando entrañan una violación continua y permanente de la legalidad objetiva consagrada en la Constitución, que afecta a una comunidad entera.

El proceso subjetivo es, en términos generales, el contencioso del restablecimiento y de la responsabilidad, el cual se desarrolla alrededor de tres elementos: la norma violada, el derecho subjetivo protegido por ella y el acto violatorio de aquélla y de éste.

\subsection{Sobre la existencia del derecho probatorio constitucional}

La revisión de la doctrina nacional y extranjera y de la jurisprudencia de la Corte Constitucional que tratan directamente sobre el tema probatorio en Acción de Tutela, llevó a la conclusión de que no existe, o no ha sido reconocido, un Derecho Probatorio Constitucional.

Sin embargo, la investigación arrojó resultados particulares en cuanto a la regla de idoneidad, el decreto, la práctica y la valoración en materia de tutela, encontrando que, para todos los medios de prueba en particular se aplica el principio de adecuación del procedimiento a las necesidades de la causa, teniendo en cuenta que el objeto de la prueba en los procesos constitucionales es averiguar la ocurrencia de un perjuicio iusfundamental, y en tal medida, como quiera que un proceso constitucional propende por la protección de los derechos reconocidos en la Constitución, existe una capitulación atenuada del debido proceso, sin que por ello puedan o deban sacrificarse las reglas de petición, ordenación, práctica y valoración, que hacen parte del iter probatorio, por desarrollar el principio de necesidad consagrado en el Código de Procedimiento Civil colombiano (aplicable por remisión directa de los decretos reglamentarios del procedimiento en tutela), según el cual, toda decisión deberá fundarse en pruebas regular y oportunamente allegadas al proceso. 


\subsection{Herramientas probatorias y medios de prueba en particular}

La investigación concluyó con la afirmación de que en procesos como el constitucional de tutela el dominio de la prueba lo tiene un juez revestido de expresas facultades oficiosas en cuanto a la prueba, así como extra y ultra petita en cuanto al derecho invocado.

Así, para determinar si un hecho que es relevante para el proceso ocurrió, el juez debe valerse de las herramientas procesales que la ley y la constitución le brindan, atendiendo a los medios de prueba previstos para el proceso en particular y a la conducencia y eficacia de cada uno de ellos, pues según las reglas especiales que rigen los procesos, lo que es conducente en un trámite no lo será igualmente para otro, tal como se expuso

Ejemplos de ello se encontraron en cada uno de los medios de prueba individualmente considerados. Así, mientras en el proceso civil no se admite copia simple de un documento en el que consta un contrato, tal restricción no impera en el proceso laboral; mientras en el derecho procesal de familia no es admisible la prueba del estado civil por declaración extrajudicial, a efectos de reconocimiento de pensiones, en el derecho procesal de la Acción de Tutela sí lo es y mientras en el derecho procesal administrativo no se presume la autenticidad de documentos y memoriales, en el derecho procesal civil es medio legal $\mathrm{y}$ admisible de prueba un documento o memorial que no ha sido autenticado o presentado personalmente ante notario (L. No 1.395 de 2010).

Otros ejemplos ilustran la conclusión: i. En el proceso civil es admisible la prueba de la confesión (art. 175 C.P.C.), pero no así en el proceso contencioso administrativo (arts. 168 C.C.A. y 199 del C.P.C.); sin embargo, a pesar de que en este último no se admite la confesión expresa ni tácita, en el trámite de tutela se reguló una situación intermedia que apunta a una confesión ficta por parte del servidor público que es sujeto pasivo de una demanda constitucional de amparo, tal como se desprende de la lectura del artículo 20 del Decreto No 2.591 de 1991, que estableció que "si el informe no fuere rendido dentro del plazo correspondiente, se tendrán por ciertos los hechos". ii. La tradicional carga estática de prueba consagrada en el artículo 177 del Código de Procedimiento Civil u onus probandi, cede o se invierte en el proceso constitucional de tutela a favor de la parte menos favorecida, en aplicación de los principios de igualdad y de solidaridad, ambos de rango constitucional. iii. Son notorias las facultades oficiosas del juez constitucional (D. No 2591 de 1991, art. 21), lo cual no se observa en la regulación procesal administrativa contenida en el Decreto No 01 de 1984, que consagra una jurisdicción emi- 
nentemente rogada. En materia penal son amplias las potestades oficiosas en materia probatoria de los jueces penales con función de control de garantías, por su doble militancia entre la Jurisdicción Ordinaria y la Constitucional, concluyendo que se trata de un juez que itera entre las dos, conclusión que lleva a afirmar que mientras el juez funge como órgano constitucional plenas son sus facultades para decretar y practicar pruebas oficiosamente, lo cual encuentra restricción cuando cumple funciones ordinarias dentro del juicio bajo las reglas adversariales del sistema penal acusatorio consagrado en la Ley No 906 de 2004. iv. Es evidente que la prueba por excelencia en el proceso de tutela es la prueba por informes (D. No 2.591 de 1991, art. 19), la cual tiene un trato definido en el Código de Procedimiento Civil (art. 243 C.P.C.), pero no así en el proceso de tutela.

Los anteriores ejemplos demuestran que la prueba de los hechos y la disciplina que se encarga de estudiar sus reglas, no es transversal en el derecho, razón por la cual ameritó adelantar una investigación que diera cuenta de dicho problema, esto es, si en efecto existe un derecho probatorio constitucional.

\section{BibLIOGRAFÍA}

Bongiovanni G., Reine (1998). Rechtslehre e dottrina giuridica dello Stato. H. Kelsen e la Costituzione austriaca de 1920, Milán, Giuffrè,

Calamandrei, Piero. (1973). Derecho procesal civil. Vol. I, Ediciones Jurídicas Europa América, Buenos Aires,

Cappelletti, Mauro. (1976). La Giurisdizione constituzionale della libertà. Milán,

Cascajo Castro, José Luis, (1975). "La jurisdicción constitucional de la libertad”, en Revista de Estudios Políticos, Madrid, núm. 199.

Colombo Campbell, Juan. Funciones del derecho procesal constitucional. Ius et Praxis, pp. 11-69. Disponible en: http://www.scielo.php?script=S07180012200200002\&Ing=es\&nrm=iso. ISSN 0718-0012.

Couture, Eduardo J. (1966). Fundamento del Derecho Procesal Civil. Ed. De Palma. $3^{a}$ Edición. Buenos Aires, p. 28.

Consejo de Estado, sentencia 180 de mayo 16 de 1991.

Corte Constitucional, Acuerdo No 01 de 1992.

Corte Constitucional, Acuerdos No 03 de 1993.

Corte Constitucional, Acuerdo No 04 de 1992.

Corte Constitucional, Acuerdo No 05 de 1992. 
Corte Constitucional, Acuerdo No 01 de 1995.

Corte Constitucional, Acuerdo No 01 de 1996.

Corte Constitucional, Acuerdo No 01 de 1997.

Corte Constitucional, Acuerdo No 01 de 1999.

Consejo de Estado, Acuerdo No 58 de 1999.

Consejo de Estado, Acuerdo No 45 de 2000.

Consejo de Estado, Acuerdo No 30 de 2002.

Consejo de Estado, Acuerdo No 31 de 2002.

Consejo de Estado, Acuerdo No 35 de 2001.

Consejo de Estado, Acuerdo No 55 de 2003.

Dueñas Ruiz, Oscar José. (2006). Acción y Procedimiento en la Tutela. Editorial Librería El Profesional, 5 a edición. Bogotá,

Ferrer Mac-Gregor, Eduardo. (2008). Derecho Procesal Constitucional origen cientifico (1928-1956), Ediciones jurídicas y sociales, Madrid,

Ferrer Mac-Gregor, Eduardo. (2006). Derecho Procesal Constitucional, Ed. Porrúa, $5^{\mathrm{a}}$ ed., México, IV Tomos. También Ferrer Mac-Gregor, Eduardo. (2008). Derecho Procesal Constitucional origen cientifico (1928-1956), Ediciones jurídicas y sociales, Madrid,

Fix-Zamudio, Héctor y Valencia Carmona, Salvador. (2001) Derecho constitucional mexicano y comparado, 2a ed., México, Porrúa.

Fix-Zamudio, Héctor, (2000). "La justicia constitucional y la judicialización de la política", en Constitución y Constitucionalismo Hoy. Cincuentenario del Derecho Constitucional Comprado de Manuel García-Pelayo, Caracas, Fundación Manuel García-Pelayo.

Garberí Lobregat, José, (2009). Constitución y Derecho Procesal. Los fundamentos constitucionales del derecho procesal, Ed. Aranzasi S.A.

García Belaunde, Domingo. (2001). Derecho Procesal Constitucional, Ed. Temis, Bogotá.

García Belaunde, Domingo. (2006). Encuesta sobre Derecho Procesal Constitucional, Ed. Porrúa, Ciudad de México, D.F.

GarCía de Enterría, Eduardo y Fernández, Tomás Ramón. (1995). Curso de Derecho Administrativo. Ed. Civitas. Tomo I. Madrid.

Giacomette Ferrer, Ana Zenobia, (2007) La prueba en los procesos constitucionales, Señal Editora, Bogotá.

GozAínI, Oswaldo Alfredo. (2006). Introducción al Derecho Procesal Constitucional, Rubinzal-Culzoni Editores, Buenos Aires. 
Hauriou, André. (1971). "Derecho Constitucional e instituciones políticas". Barcelona.

Hernández Valle, Rubén (2006). La prueba en los procesos constitucionales, Revista Iberoamericana de Derecho Procesal Constitucional, Proceso y Constitución, No 5, enero-junio 2006, Ed. Porrúa, Ciudad de México D.F., pp. 183-196.

Hurtado de BARRERA, Jacqueline. "Investigación holística: Una propuesta integrativa de la investigación y de la metodología”. En http://www.monografias. com/trabajos25/investigacion-holistica/investigacion-holistica.shtml\#refer. Citado el 6 de diciembre de 2008.

López Medina, Diego Eduardo. (2000). El derecho de los jueces: Obligatoriedad del precedente constitucional, análisis de sentencias y líneas jurisprudenciales y teoría del derecho judicial. Ediciones Uniandes y Legis. Bogotá.

Manili, Pablo Luis. (2010). Tratado de Derecho Procesal Constitucional, Ed. La Ley, Buenos Aires,

Manili, Pablo Luis. (2005). Derecho Procesal Constitucional, Ed. Universidad, Buenos Aires, Buenos Aires.

Montesquieu, Charles de Secondat. (1933). "L'Espirit del Lois". Textos de la Colección contenida en Fleiner, Derecho Administrativo. Álvarez Gendin. Madrid.

Mora, Luis Paulino, (2005). "La prueba como derecho fundamental", Revista Iberoamericana de Derecho Procesal Constitucional, Proceso y Constitución, No 4, julio-diciembre 2005, Ed. Porrúa. Ciudad de México D.F.

Morales Molina, Hernando. (1991). Curso de derecho procesal civil. Parte general, undécima edición, Editorial ABC. Bogotá

Naranjo Mesa, Vladimiro. (2006). Teoría constitucional e instituciones políticas, 10a Edición. Ed. Temis. Bogotá.

Oviedo, Amparo. (1995). Fundamentos de derecho procesal, del procedimiento y del proceso. Editorial Temis. Bogotá,

Phole, R., (1949). Verfassungsbeschwerde und Zivilprozess in Bayern, en Beiträge zum Zivilprozesrecht. Festgable zum 70 Geburtstag von Leo Rosemberg, München

Prada Tamayo, Alejandro Mauricio. (1997) "El control incidental de validez". Revista de Derecho Público No 7. Universidad de los Andes. Febrero de 1997. 
Real Academia de la Lengua Española. Diccionario de La Lengua Española. Ed. Espasa Calpe. Vigésima Primera Edición. Madrid, 1992. Tomo II.

Schmitt, Carl. (1983). La defensa de la Constitución. Editorial Tecnos. Madrid

Taruffo, Michele. (2002). La prueba de los hechos. Colección de Estructuras y Procesos, serie derecho. Traducida por Jordi Ferrer Beltrán. Ed. Trotta. Madrid.

Von Ihering, Rudolf. (1946). La Dogmática Jurídica. Editorial Losada. Buenos Aires.

Zaldívar Lelo de Larrea, Arturo. (2009). La ciencia del Derecho Procesal Constitucional, Estudios en Homenaje a Héctor Fix-Zamudio, Tomo I, Teoría General del Derecho Procesal Constitucional, Editora y Librería Jurídica GRIJLEY E.I.R.L., Ciudad de México, D.F. 
